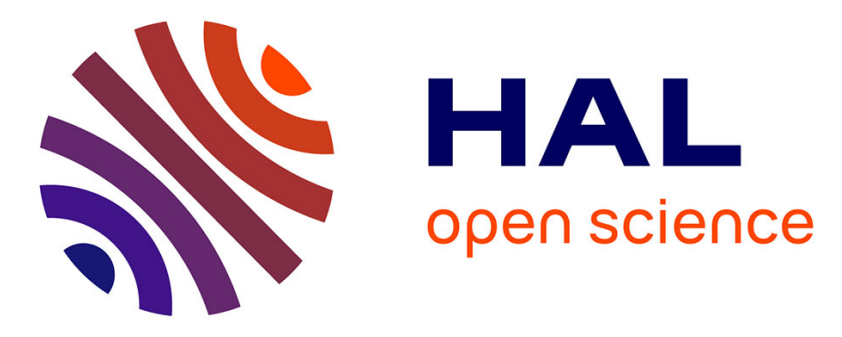

\title{
Early onset of industrial-era warming across the oceans and continents
}

Nerilie J. Abram, Helen V. Mcgregor, Jessica E. Tierney, Michael N. Evans, Nicholas P. Mckay, Darrell S. Kaufman, Kaustubh J. Thirumalai, Belen Martrat, Hugues Goosse, Steven J. Phipps, et al.

\section{To cite this version:}

Nerilie J. Abram, Helen V. Mcgregor, Jessica E. Tierney, Michael N. Evans, Nicholas P. Mckay, et al.. Early onset of industrial-era warming across the oceans and continents. Nature, 2016, 536, pp.411 418. 10.1038/nature19082. hal-01457262

\section{HAL Id: hal-01457262 https://hal-amu.archives-ouvertes.fr/hal-01457262}

Submitted on 20 Feb 2017

HAL is a multi-disciplinary open access archive for the deposit and dissemination of scientific research documents, whether they are published or not. The documents may come from teaching and research institutions in France or abroad, or from public or private research centers.
L'archive ouverte pluridisciplinaire HAL, est destinée au dépôt et à la diffusion de documents scientifiques de niveau recherche, publiés ou non, émanant des établissements d'enseignement et de recherche français ou étrangers, des laboratoires publics ou privés. 


\section{Early onset of industrial-era warming across the oceans and continents}

Nerilie J. Abram ${ }^{1,2}$, Helen V. McGregor ${ }^{3}$, Jessica E. Tierney ${ }^{4,5}$, Michael N. Evans ${ }^{6}$, Nicholas P. McKay ${ }^{7}$, Darrell S. Kaufman \& the PAGES 2k Consortium*

The evolution of industrial-era warming across the continents and oceans provides a context for future climate change and is important for determining climate sensitivity and the processes that control regional warming. Here we use postAD 1500 palaeoclimate records to show that sustained industrial-era warming of the tropical oceans first developed during the mid-nineteenth century and was nearly synchronous with Northern Hemisphere continental warming. The early onset of sustained, significant warming in palaeoclimate records and model simulations suggests that greenhouse forcing of industrial-era warming commenced as early as the mid-nineteenth century and included an enhanced equatorial ocean response mechanism. The development of Southern Hemisphere warming is delayed in reconstructions, but this apparent delay is not reproduced in climate simulations. Our findings imply that instrumental records are too short to comprehensively assess anthropogenic climate change and that, in some regions, about 180 years of industrial-era warming has already caused surface temperatures to emerge above pre-industrial values, even when taking natural variability into account.

Palaeoclimate data from the past two millennia-a period for which natural and anthropogenic climate forcings are reasonably well constrained-provide perspectives on global temperature changes during the twentieth century. Climate reconstructions of the past 2,000 years have focused mainly on the Northern Hemisphere ${ }^{1-3}$, using records derived primarily from terrestrial settings. Recent continental-scale temperature reconstructions provide evidence for twentieth century warming over all reconstruction regions except Antarctica ${ }^{4}$. A new Southern Hemisphere temperature reconstruction also demonstrates that the twentieth century is the only period of the last millennium during which warm extremes occurred simultaneously across both hemispheres ${ }^{5}$. However, these hemispheric and regional temperature histories do not allow for assessments of how past temperature changes evolved between the oceans and land.

The oceans represent a major heat reservoir, taking up more than $90 \%$ of the total global energy imbalance since the $1950 \mathrm{~s}^{6}$. Internal variability of ocean circulation mediates the global climate and, for example, is implicated in the slowdown of global atmospheric warming during the 'hiatus' interval ${ }^{7}$ (AD 2001-2014) because of the drawdown of additional heat into the subsurface ocean ${ }^{7,8}$. The existence of the recent warming slowdown is debated ${ }^{9}$; however, earlier decade-scale plateaus in the rate of warming are prominent features of the climate record ${ }^{10}$. Given the importance of the oceans in determining the pace and regional structure of changes in climate ${ }^{11}$, it is essential to understand how anthropogenic warming developed in the oceans and over land during the industrial era.

Determining an unambiguous time for the start of the industrial era is difficult, and forms part of the debate over a formal definition of the Anthropocene ${ }^{12,13}$. The Intergovernmental Panel on Climate Change (IPCC) uses 'industrial era' to refer, somewhat arbitrarily, to the time after $\mathrm{AD} 1750$, when industrial growth began in Britain, spread to other countries and led to a strong increase in fossil fuel use and greenhouse gas emissions. Here, we use the term 'industrial-era warming' to refer to the sustained, significant $(P<0.1)$ warming of Earth's climate that developed during the industrial era. We use the palaeoclimate history since AD 1500 as a context for assessing the evolution of industrial-era warming across surface-ocean and land areas. Our assessments use newly developed regional sea-surface temperature (SST) reconstructions for the tropical oceans ${ }^{14}$ and SST-sensitive records for the global oceans ${ }^{14,15}$, along with continental-scale temperature reconstructions and databases ${ }^{4,16}$ (Fig. 1, Methods). We compare the onset of industrial-era warming in these palaeoclimate datasets to transient multimodel climate simulations driven by full natural and anthropogenic forcings ${ }^{17}$. We also use experiments with single $\mathrm{e}^{18-20}$ and cumulative $e^{21}$ external climate forcings to investigate the factors that define the onset of industrial-era warming.

\section{Regional features of industrial-era warming}

Synthesis of marine palaeoclimate records spanning the past 2,000 years has identified a robust global surface-ocean cooling trend that reached coolest conditions during the period AD $1400-1800^{15}$. This finding is qualitatively consistent with pre-industrial cooling trends in terrestrial records and can be explained by an increased frequency of explosive volcanism during the past millennium ${ }^{15,22}$. Marine records with moderate-to-high $(<25 \mathrm{yr})$ temporal resolution indicate that, in many regions, this long-term SST cooling trend reversed during the industrial era ${ }^{14,15}$, including in the tropical oceans where robust regional SST reconstructions spanning the past four centuries have been developed using coral archives ${ }^{14}$. Industrial-era warming in the area-weighted average of regional tropical SST reconstructions is visually similar to warming of the global area-weighted mean of terrestrial temperature reconstructions ${ }^{4}$ (Fig. 1c, d). In particular, the average



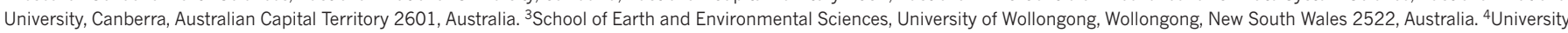

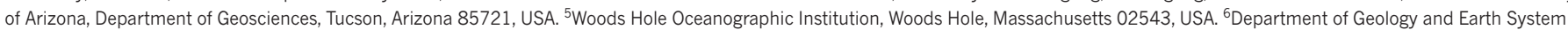
Science Interdisciplinary Center, University of Maryland, College Park, Maryland 20742, USA. ${ }^{7}$ School of Earth Sciences and Environmental Sustainability, Northern Arizona University, Flagstaff, Arizona 86011, USA.

*A list of participants and their affiliations appears at the end of the paper.
} 
a

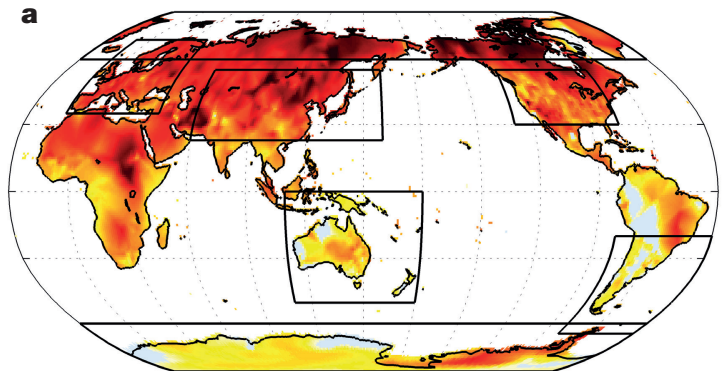

b
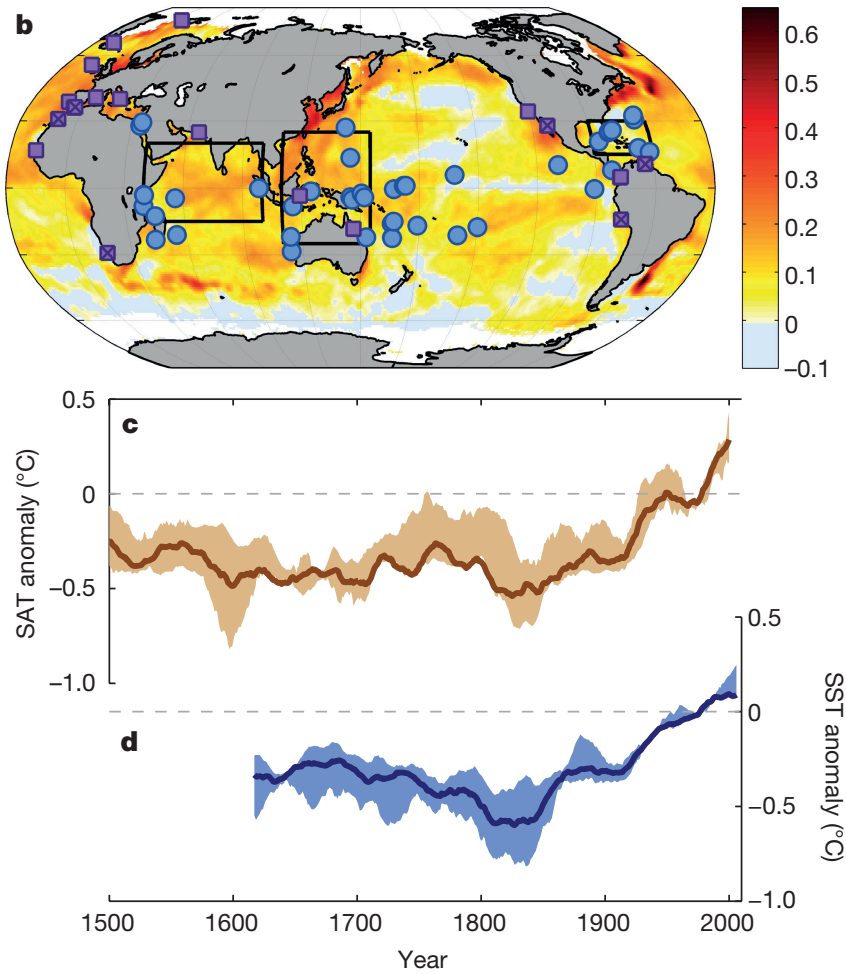

Figure 1 Terrestrial and marine palaeoclimate reconstructions. a, b, Instrumental temperature trends over the period AD 1961-2010 for surface air temperature (SAT; $\mathbf{a}$ ) and sea surface temperature (SST; b). The black boxes indicate the PAGES $2 \mathrm{k}$ continental-scale reconstruction regions ${ }^{4}$ (a) and the PAGES Ocean2k high-resolution (annual) reconstruction regions ${ }^{14}(\mathbf{b})$. The symbols in $\mathbf{b}$ indicate the locations of highly resolved ${ }^{14}$ (blue circles; Extended Data Table 1) and moderately resolved ${ }^{15}(<25 \mathrm{yr}$, purple squares; crossed squares indicate ocean upwelling sites; Extended Data Fig. 7) marine palaeo-SST proxy records. c, d, 25-year moving averages of the area-weighted mean terrestrial temperature anomaly (brown line) , $^{16}$ and the $25 \%-75 \%$ range across continental-scale reconstructions (shading) (c) and area-weighted mean tropical SST anomaly (blue line) and minimum-maximum range across the Indian, western Pacific and western Atlantic reconstructions ${ }^{14}$ (shading) (d). Anomalies are relative to the AD 1961-1990 mean (dashed lines).

terrestrial and tropical ocean temperature histories show industrial-era warming developing after AD 1800, with similar multi-decadal expressions of accelerated and reduced warming phases.

The similarity of average terrestrial and marine temperature histories (Fig. 1c, d) masks important regional differences in industrial-era warming (Fig. 2, Extended Data Fig. 1). To examine these regional features, we first assess when sustained, significant warming began in the regional temperature reconstructions. We define a sustained, significant trend as the most recent trend that persists until the end of the reconstruction and that is significantly different from zero above the $90 \%$ confidence level $(P<0.1)$. We determine the median time of onset of these sustained trends across different levels of smoothing (15-50 y) applied to the regional reconstructions (Methods, Extended
Data Fig. 2a) ${ }^{23,24}$. The strengths and limitations of this and other change-point detection methods in assessing the onset of industrial-era warming are explored using synthetic time series (Methods, Extended Data Fig. 3). Model-based testing suggests that estimates for warming onset are insensitive to the seasonal preference that exists in some regional reconstructions ${ }^{4}$ (Methods, Extended Data Fig. 4).

Sustained, significant warming began in the tropical oceans around the 1830s, with no discernible difference in onset across the three tropical SST reconstruction regions (Fig. 2a, Table 1, Extended Data Fig. 1a, b). The onset of tropical-ocean warming is similar to the median onset of warming in Northern Hemisphere mean temperature ${ }^{3}$ (Extended Data Fig. 1a), although the Northern Hemisphere ensemble also includes a sub-member where recent warming is not sustained to the end of the reconstruction (Supplementary Fig. 1). This exception is due to strong multi-decadal variability, which is common to each of the Northern Hemisphere mid-latitude continental regions and can delay the detection of sustained warming trends at narrow filter widths (Extended Data Fig. 5). Nevertheless, each of the Northern Hemisphere regional-scale reconstructions also displays mid-nineteenth-century onsets for industrial-era warming (Fig. 2a, Table 1, Extended Data Fig. 1a, b).

In contrast to the mid-nineteenth-century onset of warming in the tropical oceans and the Northern Hemisphere, the Southern Hemisphere onset of industrial-era warming appears delayed (Fig. 2a, Table 1). In hemispheric-scale reconstructions ${ }^{3,5}$, the median estimate for the onset of sustained warming is approximately 50 years later in the Southern Hemisphere than the Northern Hemisphere (Extended Data Fig. 1a, Supplementary Fig. 1). The regional structure of this apparent Southern Hemisphere lag involves sustained, significant warming developing over Australasia and South America around the start of the twentieth century, while significant continent-scale warming is not detected for Antarctica (Table 1, Extended Data Fig. 1a). The Antarctic reconstruction has the greatest uncertainty of the regional reconstructions ${ }^{4}$ (Methods), and significant warming has been documented over the Antarctic Peninsula and West Antarctica since the mid-twentieth century ${ }^{23,25}$. However, the absence of significant Antarctic warming at the continent scale is corroborated by post-1979 satellite observations averaged across Antarctica ${ }^{26}$.

Industrial-era warming across the oceans and continents is further investigated by examining the rates of regional warming. All centuryscale linear trends in the regional reconstructions since AD 1500 are calculated (100-yr trends with 1-yr time step; Supplementary Video 1) and the distributions of trends beginning since AD 1800 are used to assess the regional rates of industrial-era warming. For each tropical ocean and Northern Hemisphere regional reconstruction, the distribution of century-scale trends starting after AD 1800 has a clear positive shift compared to earlier trends (Fig. 2b, Table 1, Extended Data Fig. 1c) and includes the largest century-scale warming trend of the past 500 years. Temperature trends in the Arctic since AD 1800 are greater than in any other region, indicative of Arctic amplification ${ }^{27}$. The similarity of post-AD 1800 trends for the tropical Indian and western Atlantic oceans with those in Europe, Asia and North America (Table 1), indicates that industrial-era warming of the tropical oceans has progressed at a rate similar to warming of the Northern Hemisphere mid-latitude continents. By contrast, rates of century-scale warming since $\mathrm{AD} 1800$ in the Southern Hemisphere regional reconstructions are slower than for the tropical oceans and Northern Hemisphere continents (Fig. 2b, Table 1). This difference may be related to the delayed onset of warming in the Australasia and South America reconstructions, but is also consistent with instrumental evidence for hemispheric asymmetries in the rate of twentieth-century warming (Fig. 1a, b). For Antarctica, the absence of continent-scale warming during the industrial era results in pre- and post-AD 1800 trend distributions that are statistically indistinguishable (Extended Data Fig. 1c).

The time when a climate-change signal exceeds the range of climate variability is known as the time of emergence ${ }^{28}$. The time of emergence 


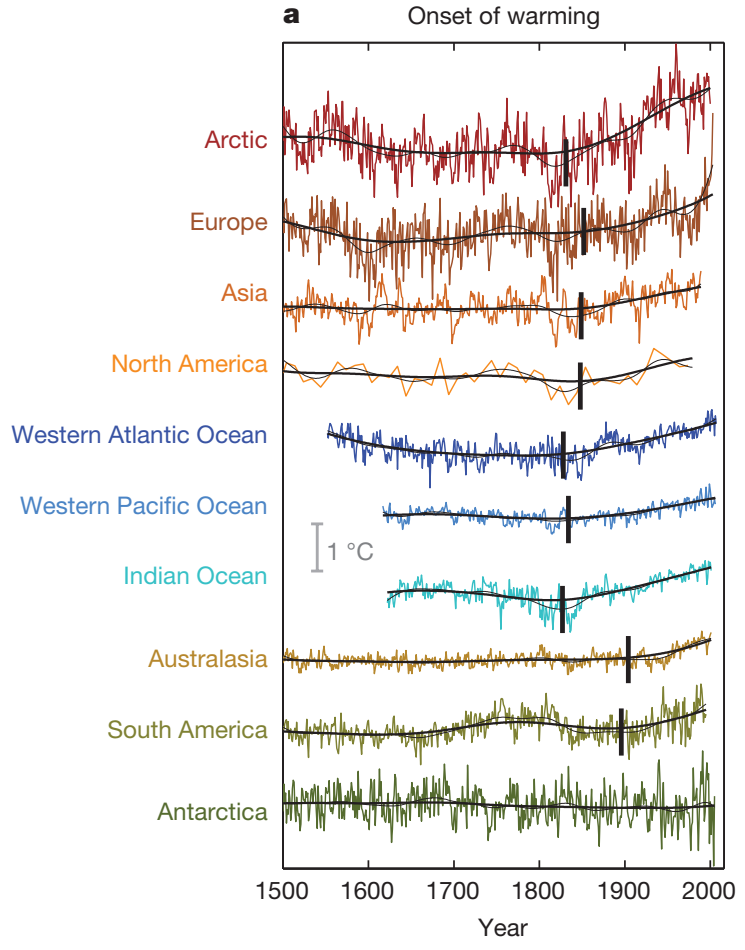

Figure 2 | Onset and magnitude of industrial-era warming in regional temperature reconstructions. a, Regional reconstructions ${ }^{4,14}$ since AD 1500 (coloured lines) with 15-yr (thin black lines) and 50-yr (thick black lines) Gaussian smoothing, shown alongside the median time of onset for sustained, significant industrial-era warming assessed across 15-50-yr filter widths (vertical black bars) (Methods, Extended Data Fig. 2a). Grey $1{ }^{\circ} \mathrm{C}$ scale bar denotes the $y$-axis scale of each regional temperature reconstruction. $\mathbf{b}$, Histograms of century-scale regional trends, comparing those beginning during the period AD 1500-1799 (grey bars) with those beginning since AD 1800 (coloured bars). The heights

for industrial-era warming depends on (i) when warming began, (ii) the rate of warming and (iii) the magnitude of interannual to multidecadal climate variability. Time-of-emergence studies typically use twentieth century instrumental data or post-1850 (historical) simulations to characterize the baseline climate, and have commonly concluded that unprecedented climates will emerge first in tropical air temperatures because of the small magnitude of interannual temperature variability in these region $\mathrm{s}^{28-30}$. However, our findings of a mid-nineteenth-century onset of industrial-era warming suggest that, in some regions, the entire instrumental period contains a signature of climate warming, rendering it unsuitable for determining climate emergence. We use the multicentury context available from the regional palaeoclimate reconstructions, and a pre-AD 1800 reference period (Methods), to assess the extent to which industrial-era warming may have already emerged in regional climates.

Industrial-era warming led to the emergence of regional climate change first in the Arctic (Fig. 2c, Table 1). Despite the large variability of Arctic climate, the palaeoclimate time-of-emergence assessment indicates that the early onset and rapid rate of warming resulted in the emergence of climate change during the 1930s (approximately 100 years after sustained, significant warming began). The tropical ocean regions display a similar rate of warming to that of the Northern Hemisphere mid-latitude continents, but the industrial-era warming signal emerges sooner in the tropical oceans (time of emergence at around AD 1948-1962) because of the smaller magnitude of variability there. Emergence of industrial-era warming for Australasia is around AD 1960, because the delayed onset of warming is compensated by the small magnitude of interannual variability in this regional reconstruction. All other regions apart from Antarctica are nearing $100-y r$ trend distributions

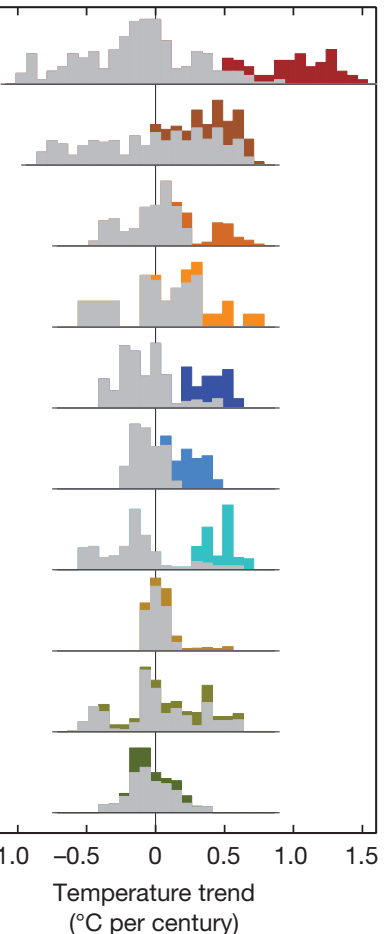

c

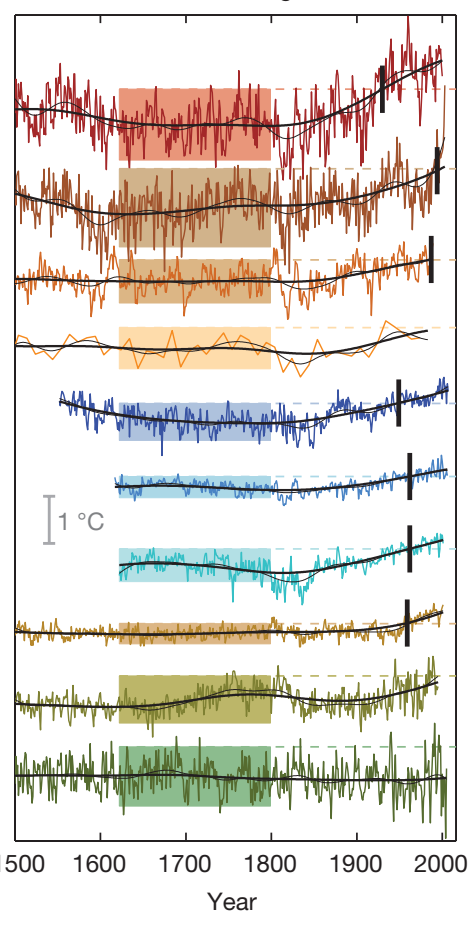

of the bars are normalized by the maximum occurrence across each region to aid visual representation. See Supplementary Video 1 for temporal evolution of century-scale trends. c, Regional reconstructions (coloured lines) with 15-yr (thin black lines) and 50-yr (thick black lines) filters, shown alongside the $\pm 2 \sigma$ range (shaded boxes) of interannual variability over the AD 1622-1799 reference period ( $+2 \sigma$ level continued by dashed lines). The median time of climate emergence (vertical black bars) is defined as the time at which the climate signal (15-50-yr width filters of the regional reconstructions) first exceeds and remains above the $+2 \sigma$ threshold of the reference period (Methods).

the emergence of warming above the threshold of pre-industrial climate variability by the start of the twenty-first century (the end of the reconstructions).

Our regional palaeoclimate assessments suggest that widespread climate warming observed during the twentieth century forms part of a sustained trend that began in the tropical oceans and over some Northern Hemisphere land areas around the 1830s (about 180 years ago). Although caveats exist relating to the accuracy with which regional palaeoclimate reconstructions represent past temperature changes ${ }^{4,14-16}$, our multi-century assessments clearly demonstrate the need to incorporate pre-twentieth-century information in comprehensive assessments of industrial-era warming. The early onset of industrialera warming may not alter the conclusions of time-of-emergence studies focused on protecting infrastructure built during recent decades ${ }^{31}$; however, our findings imply that time-of-emergence studies that rely on a twentieth-century baseline may underestimate how soon the effects of climate change will fall outside the range of climate variability to which natural systems are adapted ${ }^{30}$.

\section{Climate forcing of industrial-era warming}

Model simulations provide an important tool for investigating which forcings are most consistent with the reconstructed onset of industrial-era warming. We examine the regional responses of global climate model simulations to natural and anthropogenic forcings since AD 1500, applying the same trend-detection methodology used for the palaeoclimate reconstructions (Methods). An ensemble of ten different models reproduces the near-synchronous mid-nineteenth-century onset of sustained, significant warming observed for reconstructed Northern Hemisphere surface air temperature and tropical SST 


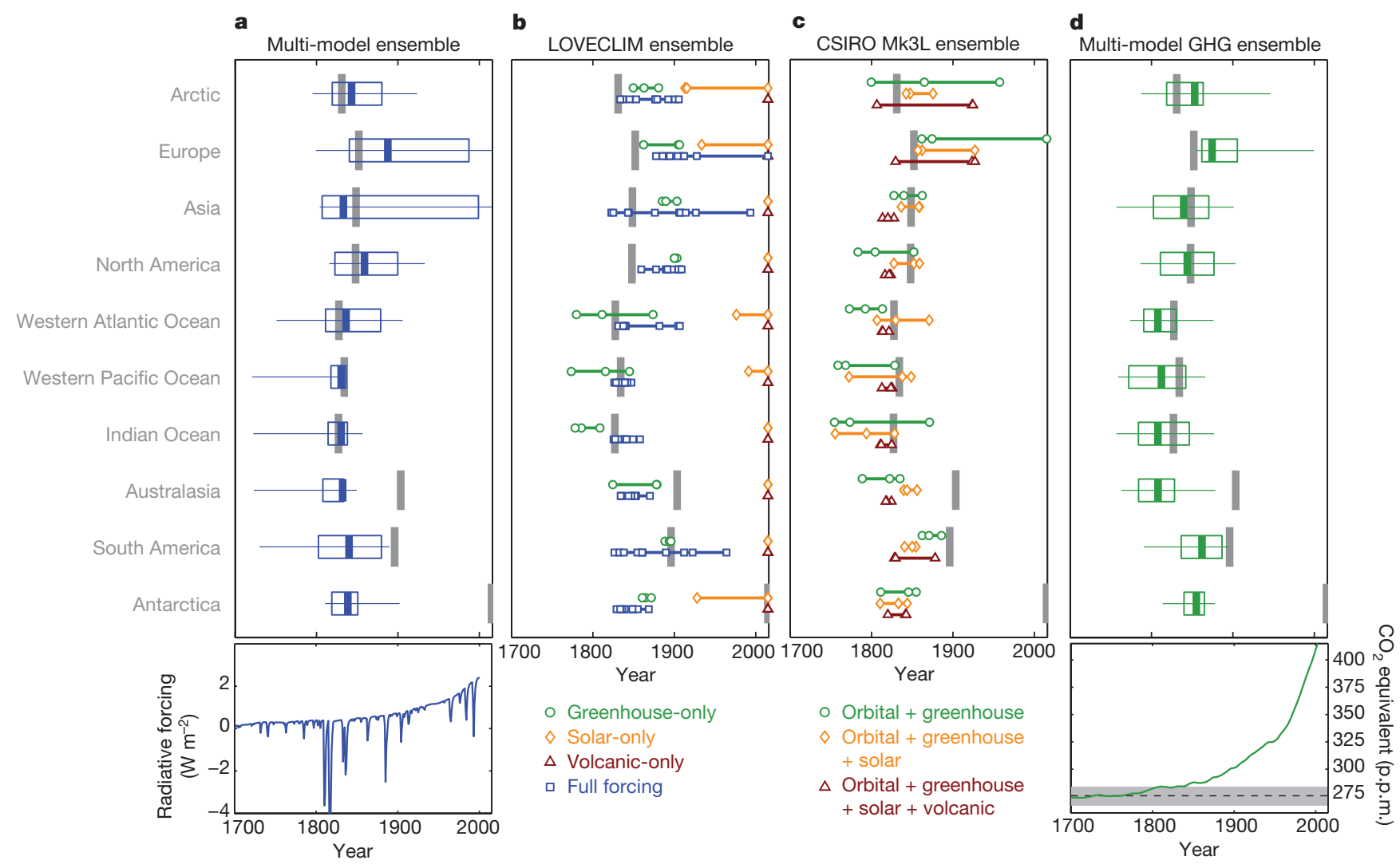

Figure 3 | Data-model comparison of the onset of industrial-era warming. a-d, Median onset of sustained, significant warming in regional reconstructions (vertical grey bars; as in Fig. 2a, vertical black bars) compared to various ensemble results. a, Median (vertical blue bars), $25 \%-75 \%$ range (boxes) and 5\%-95\% range (horizontal lines) of the corresponding regional median warming onsets across ten multi-model lastmillennium climate simulations with full radiative forcings (Supplementary Fig. 1). b, Median timing (open symbols) of warming onset across threemember ensembles for single radiative forcing experiments (green circles, orange diamonds and red triangles) and a ten-member ensemble with full radiative forcings (blue squares) using the LOVECLIM model ${ }^{18}$. $\mathbf{c}$, Median

(Fig. 3a, Table 1). Palaeoclimate data-model agreement is particularly good for Northern Hemisphere terrestrial regions, where the patterns of short-term cooling caused by volcanic eruptions and sustained recent warming from greenhouse gas emissions are remarkably similar (Extended Data Fig. 2). The agreement between the multimodel ensemble and palaeoclimate reconstructions suggests that the onset of industrial-era warming over Northern Hemisphere landmasses and in the tropical oceans is consistent with a forced climate response.

By contrast, none of the climate models show evidence for a delayed Southern Hemisphere onset of industrial-era warming (Fig. 3a). A ten-member ensemble of LOVECLIM simulations also suggests that the delayed development of warming over Antarctica and Australasia is not explicable within the range of unforced climate variability in that model (Fig. 3b). Instead, the evolution of regional temperature trends in the multi-model ensemble mean (Extended Data Fig. 2b) and within individual models (Supplementary Fig. 2) shows a globally synchronous thermodynamic response of surface temperatures to external climate forcings. Previous palaeoclimate studies have noted that climate models tend to overemphasize Northern HemisphereSouthern Hemisphere synchronicity of past temperature changes ${ }^{5,32}$, perhaps by overestimating externally forced climate responses in the Southern Hemisphere and/or underestimating the magnitude of Southern Hemisphere climate variability ${ }^{32}$. Unresolved or inaccurate physical processes in model representations of the Southern timing (open symbols) of warming onset for three-member ensembles of CSIRO Mk3L simulations using cumulative radiative forcing experiments ${ }^{21}$. d, Median (green vertical bars), 25\%-75\% range (boxes) and 5\%-95\% range (horizontal lines) of regional median warming onsets for 13 ensemble members across four different climate models forced with only greenhouse gas changes ${ }^{18-21}$. Lower panel in a shows the corresponding full radiative forcing (from orbital, greenhouse gas, solar and volcanic sources) ${ }^{17}$. Lower panel in $\mathbf{d}$ shows the corresponding equivalent atmospheric $\mathrm{CO}_{2}$ concentration relative to the mean (dashed line) and \pm 1.5 interquartile range (grey shading; outlier test) of an $\mathrm{AD} 0-1500$ baseline interval. See Extended Data Table 2 for model details.

Hemisphere ocean-atmosphere-cryosphere systems also hinder the accurate simulation of Southern Hemisphere climate ${ }^{26,33}$ including the overestimation of simulated Antarctic region warming compared with satellite observations of recent surface air and ocean temperature trends ${ }^{26}$. The paucity of climate observations also hinders attempts to resolve differences between observations and simulations in the Southern Hemisphere ${ }^{26,32}$. As a result, currently available model output cannot reasonably be used to assess the delayed onset of Southern Hemisphere industrial-era warming that is suggested by palaeoclimate observations.

Naturally forced climate cooling may have helped to set the stage for the widespread onset of industrial-era warming in the tropical oceans and over Northern Hemisphere landmasses during the mid-nineteenth century. Episodic cooling caused by the large 1815 Tambora volcanic eruption is prominent in Northern Hemisphere terrestrial temperature reconstructions (Fig. 2a). In last-millennium model simulations, the strong cooling caused by the Tambora eruption is followed immediately by a decade-scale interval of accelerated global warming as the climate recovers ${ }^{34}$. The Dalton solar minimum also occurred in the early nineteenth century, but solar forcing is thought to have only a small influence on last-millennium climate compared to the effects of volcanic eruptions ${ }^{20}$. In the CSIRO Mk3L experiments, in which forcings were applied cumulatively rather than individually, it is particularly the addition of volcanic forcing that tends to focus the onset of industrialera warming into a narrower time window-both between regions and 
Table 1 | Onset, rate and emergence of industrial-era warming in reconstructions and simulations

\begin{tabular}{|c|c|c|c|c|c|}
\hline & \multicolumn{2}{|c|}{$\begin{array}{c}\text { Year of onset of sustained, significant } \\
\text { warming trends }\end{array}$} & \multirow{2}{*}{\multicolumn{2}{|c|}{$\begin{array}{c}\text { Century-scale trend distribution } \\
\left({ }^{\circ} \mathrm{C} \text { per century) }\right. \\
\text { Reconstructions }\end{array}$}} & \multirow{3}{*}{$\begin{array}{c}\text { Year of emergence } \\
\text { Reconstructions }\end{array}$} \\
\hline & \multirow[t]{2}{*}{ Reconstructions } & \multirow[t]{2}{*}{ Simulations } & & & \\
\hline & & & AD 1500-1799 & Since AD 1800 & \\
\hline Arctic & 1831 & $1843(1819-1880)$ & $-0.11(-0.41-0.07)$ & $1.07(0.92-1.26)$ & 1930 \\
\hline Europe & 1852 & $1888(1840-1987)$ & $0.02(-0.39-0.33)$ & $0.46(0.29-0.58)$ & $1994^{\ddagger}$ \\
\hline Asia & 1849 & 1833 (1807-1999) & $0.00(-0.18-0.10)$ & $0.48(0.35-0.54)$ & $1987^{\ddagger}$ \\
\hline North America & 1847 & 1859 (1823-1900) & $0.01(-0.38-0.15)$ & $0.48(0.29-0.52)$ & $\S$ \\
\hline Western Atlantic Ocean & 1828 & $1836(1811-1879)$ & $-0.11(-0.21-0.01)$ & $0.41(0.27-0.51)$ & 1948 \\
\hline Western Pacific Ocean & 1834 & $1830(1818-1836)$ & $-0.09(-0.13-0.02)$ & $0.27(0.19-0.35)$ & 1962 \\
\hline Indian Ocean & 1827 & 1830 (1814-1838) & $-0.14(-0.31--0.04)$ & $0.51(0.39-0.54)$ & 1962 \\
\hline Australasia & $1904^{*}$ & $1832(1808-1833)$ & $0.00(-0.04-0.05)$ & $0.07(0.02-0.23)$ & 1959 \\
\hline South America & 1896 & $1840(1802-1880)$ & $-0.02(-0.11-0.21)$ & $0.20(-0.02-0.38)$ & $\S$ \\
\hline Antarctica & + & $1839(1819-1851)$ & $-0.05(-0.15-0.09)$ & $-0.06(-0.14-0.07)$ & $\S$ \\
\hline
\end{tabular}

Statistics represent changes in surface air temperature (SAT) for continental reconstruction regions and sea surface temperature (SST) for tropical ocean regions. The values given are medians (inter-model medians for the simulations), with the 25\%-75\% ranges in parentheses. The reconstructed median years of onset and emergence are determined using $15-50$-yr filter widths. Visual representations of the data are found in Fig. $2 \mathrm{a}$ (onset of warming in reconstructions), Fig. 3a (onset of warming in simulations), Fig. 2b (rates of warming) and Fig. 2c (climate emergence). "Compared with a median warming onset of AD 1886 in the original Australasia $2 \mathrm{k}$ reconstruction ${ }^{4}$ that includes marine SST-sensitive records.

†Sustained, significant warming never achieved in reconstruction.

${ }^{\dagger}$ Emergence of industrial-era warming above the AD 1622-1799 (reference interval) variability was within 20 years of the end of the reconstruction, making permanent emergence uncertain.

§Emergence was not achieved in reconstruction.

between ensemble members for the same region-compared to experiments run with greenhouse forcing alone (Fig. 3c).

Simulations suggest that recovery from volcanic cooling is not an essential requirement for reproducing the mid-nineteenth-century onset of industrial-era warming. Multi-model experiments forced with only greenhouse gases capture regional onsets for sustained industrial-era warming that are consistent with the tropical ocean and Northern Hemisphere continental reconstructions (Fig. 3d). Testing of our change-point detection method also indicates that volcanic-style cooling events do not substantially alter the onset determined for sustained warming trends in synthetic time series (Methods, Extended Data Fig. 3a, b). We conclude that greenhouse forcing of industrial-era warming began by the mid-nineteenth century, but that the confluence of explosive volcanic eruptions around this time was probably also influential in aligning the onset of warming over tropical ocean and Northern Hemisphere land regions.

\section{Mechanisms of industrial-era warming}

Our regional palaeoclimate assessments show that the thermodynamic response to increasing greenhouse gas concentrations developed in the oceans and atmosphere even when anthropogenic contributions were small. The spatial fingerprint of the onset of industrial-era warming may further elucidate the role of the oceans in the development of anthropogenic warming. We explore this by assessing change-points in the site-level palaeoclimate records that contribute to the marine ${ }^{14,15}$ and terrestrial ${ }^{4,16}$ temperature reconstructions (Extended Data Fig. 6). Onset estimates from site-level records are more variable than for the regional reconstructions. This variation arises from (i) lower trend-to-variability (or signal-to-noise) ratios in individual palaeoclimate records, (ii) varying lengths of the individual records that do not always include information before the onset of sustained industrial-era trends and (iii) differences in how representative each record is of local temperature. Issues similar to (i) and (ii) limit the detection and attribution of climate change at subregional scales from climate observations and simulations ${ }^{35}$. For these reasons, we view the site-level analyses in only a qualitative sense (Fig. 4), using them to aid the more robust assessments derived from regional reconstructions (Fig. 2).

Sustained, significant warming trends developed during the industrial era across the majority $(71 \%, n=55)$ of marine records (Extended Data Fig. 6a). This complements similar findings of widespread recent warming trends in site-level palaeoclimate records from predominantly terrestrial environments ${ }^{4}$. Development of sustained warming during the nineteenth century in individual records from the tropical oceans and in Northern Hemisphere mid- and high-latitude terrestrial records
(Fig. 4) corroborate our findings based on the regional reconstructions. Some Southern Hemisphere mid-latitude terrestrial records also show this early warming (Fig. 4a), suggesting that although continental-scale temperature reconstructions for Australasia and South America indicate a delayed onset of industrial-era warming (Fig. 2), this may not be representative of all Southern Hemisphere mid-latitude land areas (Fig. 4a).

The early onset of industrial-era warming of the tropical oceans was widespread; however, industrial-era climate changes may have resulted in localized surface-ocean cooling in some settings (Extended Data Figs 6b, 7a). Previous assessments of the moderately resolved marine records cautiously concluded that qualitative warming and cooling trends during the twentieth century were produced if the records were composited into a priori defined non-upwelling and upwelling subsets, or if the records were composited by tropical versus Northern Hemisphere extratropical location, or by proxy type ${ }^{15}$. Our change-point assessment of the moderately resolved marine records finds that the most distinct differentiation between recent cooling and warming trends occurs when the records are separated into upwelling and non-upwelling sites (Extended Data Fig. $7 b-d)$. Therefore, enhanced ocean upwelling may be the most plausible mechanism for explaining the recent cooling trends detected at some marine sites, consistent with theories that climate warming could, in some locations, cause strengthening of the surface winds that generate coastal upwelling ${ }^{36-38}$.

The early development and rapid rate of tropical ocean warming during the industrial era (Figs 2, 4b) may corroborate model-based descriptions of an enhanced equatorial response of the oceans to increased greenhouse forcing 39,40 . The warming near the equator as a result of an enhanced equatorial response is caused by increased surface ocean stability and a reduction in surface evaporative cooling due to the combination of lower wind speed and relative humidity. The hypothesized enhanced-equatorial-response mechanism and spatial fingerprint differs from an El Niño-like response of the tropical oceans to global warming (requiring weaker Walker circulation, reduced eastern Pacific upwelling and reduced east-west SST gradient ${ }^{41}$ and shows greater consistency between models ${ }^{39}$. A regional SST reconstruction for the eastern Pacific, although not used in our study because it is thought to have a spuriously large twentieth-century trend attributed to hydrologic effects ${ }^{14}$, indicates that sustained, significant warming of eastern Pacific SST began markedly later (around AD 1913) than in the other tropical ocean regions ${ }^{14}$. Full-forcing and greenhouse-only climate model simulations assessed spatially at a grid resolution of $5^{\circ} \times 5^{\circ}$ (Extended Data Fig. 8) also display a delayed onset of industrialera warming in the eastern Pacific over a narrow region along the 

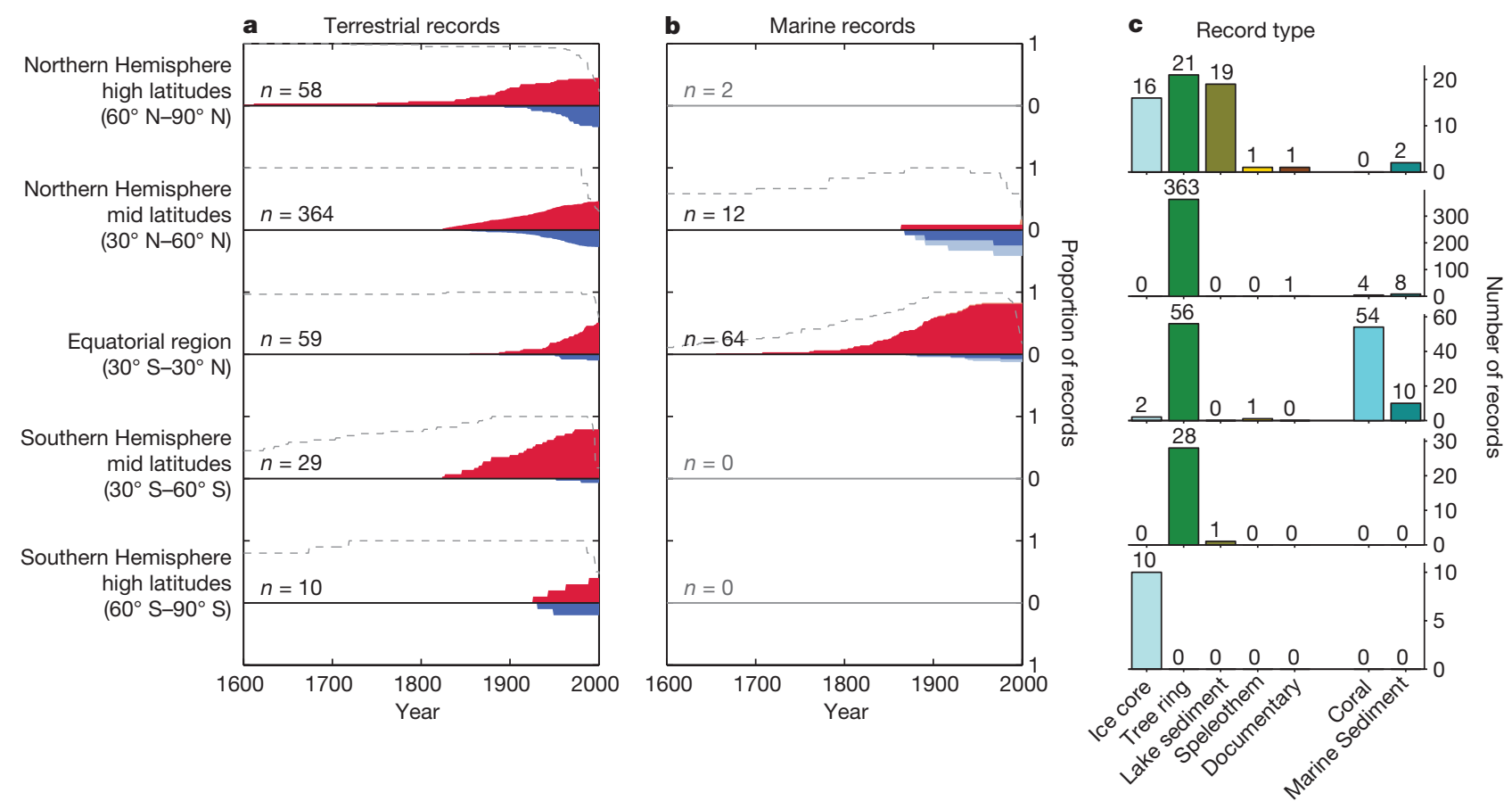

Figure 4 | Latitudinal development of site-level temperature trends. a, b. Cumulative distributions for terrestrial (a) and marine (b) records, showing latitudinal development of sustained significant warming (red; upward) or cooling (blue; downward) trends across the site-level records (Extended Data Fig. 6). The distributions are expressed as a proportion of total records within each latitudinal band (number of total records, $n$, indicated; grey values indicate an insufficient number of site-level records $(n \leq 2)$ for meaningful comparison). Light shading in $\mathbf{b}$ denotes trends at marine sediment core sites with an a priori upwelling regime (Extended

equator, distinct from the otherwise widespread early onset of tropical surface ocean warming (Extended Data Fig. 8, Supplementary Fig. 3). The delayed detection of sustained, significant warming in the eastern Pacific may be influenced by large-amplitude interannual variability there (Extended Data Fig. 3b, c), which limits our ability to confidently evaluate El Niño (or La Niña)-like dynamic mechanisms in defining the onset of industrial-era warming across the oceans. Nevertheless, the early onset of industrial-era warming in tropical ocean regions away from the equatorial eastern Pacific, in reconstructions and simulations, appears to support an enhanced equatorial response in the SST changes caused by global warming.

Widespread warming of tropical SSTs during the industrial era (Figs 2, 4b) may have had global importance because of the nonlinear influence of tropical SSTs on deep atmospheric circulation, which redistributes heat and moisture. The latitudinal development of terrestrial warming that we observe across individual palaeoclimate records (Fig. 4a) is similar to that reported for twentiethcentury terrestrial air temperature observations ${ }^{42}$. In that study it was proposed that twentieth-century terrestrial warming focused over the Northern Hemisphere subtropical-subpolar regions and in a narrow band over the Southern Hemisphere subtropics could be indicative of anthropogenically forced widening of the tropics through expansion of the Hadley circulation cells ${ }^{42}$. The causes of recent multi-decadal episodes of contraction and expansion of Hadley circulation ${ }^{43,44}$ have proven difficult to resolve because of the brevity of observational datasets. However, numerous studies suggest that tropical ocean warming is essential for reproducing the recent poleward expansion of the Hadley circulation, because of the effect of SST on tropospheric temperature, tropopause height, and baroclinic wave position and stability ${ }^{45,46}$. Further assessments of marine and terrestrial palaeoclimate networks, including compilations of hydroclimate-sensitive records currently in development, have the potential to provide a context
Data Fig. 7), for which the localized SST response ${ }^{36-38}$ to regional climate warming may not be representative of latitudinal average climate. Dashed lines show the temporal coverage of site-level records (expressed as a proportion of latitudinal band total, $n$ ). c, The number and type of proxy records available by latitudinal band (bars are coloured by archive type). Because of the varying length of individual records, not all of which cover the full interval of industrial-era warming (particularly tropical corals), we use these data only as a qualitative indicator of the relative timing of the onset of industrial-era warming between different latitudinal bands.

for the role of rapid tropical ocean warming during the industrial era in widening the tropical climate belt.

Differences between Southern Hemisphere reconstructions and simulations, and the lack of suitable palaeoclimate records from the extratropical Southern Hemisphere oceans, currently preclude an assessment of the role of the oceans in the delayed onset of Antarctic warming that is seen in regional (Fig. 2) and site-level (Fig. 4a) palaeoclimate analyses, and in observational records ${ }^{26}$. Idealized model experiments of ocean heating predict a centennial-scale delayed onset of anthropogenic warming in the Southern Ocean caused by upwelling of unmodified subsurface water and northward advection of any surface warming signal $^{11,47}$. The strengthening of westerly winds over the Southern Ocean during the twentieth century, related to the Southern Annular Mode $^{48}$, have probably also influenced the delayed development of sustained industrial-era warming over Antarctica. In the Northern Hemisphere, the scarcity of suitable marine palaeoclimate records from the mid- to high latitudes also precludes an assessment of ocean-land relationships during the onset of industrial-era warming. However, we find that in full-forcing and greenhouse-only simulations the onset of sustained surface ocean warming in the North Atlantic Ocean is delayed, or instead is characterized by cooling (Extended Data Fig. 8). This finding is consistent with reports of an unusual slowdown of Atlantic Meridional Overturning Circulation during the twentieth century ${ }^{49}$. Increasing knowledge of the temperature evolution of the extratropical oceans before and during the industrial era should be considered a key target for future palaeoclimate research.

The spatial development of industrial-era warming across the oceans and continents demonstrates that the tropical oceans and Northern Hemisphere were particularly responsive to the climate forcings that shaped industrial-era warming. The mid-nineteenth-century commencement of industrial-era warming suggests that Earth's surface temperature may respond to even small increases in greenhouse gas 
forcing more rapidly than previously thought ${ }^{50}$, and highlights the importance of multi-century palaeoclimate records and model simulations in assessing the response of worldwide climate to anthropogenic greenhouse gas emissions.

Online Content Methods, along with any additional Extended Data display items and Source Data, are available in the online version of the paper; references unique to these sections appear only in the online paper.

\section{Received 9 June 2015; accepted 28 June 2016.}

1. Hegerl, G. C., Crowley, T. J., Hyde, W. T. \& Frame, D. J. Climate sensitivity constrained by temperature reconstructions over the past seven centuries. Nature 440, 1029-1032 (2006).

2. Mann, M. E. et al. Proxy-based reconstructions of hemispheric and global surface temperature variations over the past two millennia. Proc. Natl Acad. Sci. USA 105, 13252-13257 (2008).

3. Frank, D. C. et al. Ensemble reconstruction constraints on the global carbon cycle sensitivity to climate. Nature 463, 527-530 (2010).

4. PAGES $2 \mathrm{k}$ Consortium. Continental-scale temperature variability during the past two millennia. Nat. Geosci. 6, 339-346 (2013).

5. Neukom, R. et al. Inter-hemispheric temperature variability over the past millennium. Nat. Clim. Chang. 4, 362-367 (2014).

6. Levitus, S. et al. World ocean heat content and thermosteric sea level change (0-2000 m), 1955-2010. Geophys. Res. Lett. 39, L10603 (2012).

7. England, M. H. et al. Recent intensification of wind-driven circulation in the Pacific and the ongoing warming hiatus. Nat. Clim. Chang. 4, 222-227 (2014).

8. Chen, X. \& Tung, K.-K. Varying planetary heat sink led to global-warming slowdown and acceleration. Science 345, 897-903 (2014).

9. Karl, T. R. et al. Possible artifacts of data biases in the recent global surface warming hiatus. Science 348, 1469-1472 (2015)

10. Crowley, T. J., Obrochta, S. P. \& Liu, J. Recent global temperature "plateau" in the context of a new proxy reconstruction. Earths Futur. 2, 281-294 (2014).

11. Marshall, J. et al. The ocean's role in the transient response of climate to abrupt greenhouse gas forcing. Clim. Dyn. 44, 2287-2299 (2015)

12. Lewis, S. L. \& Maslin, M. A. Defining the Anthropocene. Nature 519, 171-180 (2015).

13. Ruddiman, W. F. The Anthropocene. Annu. Rev. Earth Planet. Sci. 41, 45-68 (2013).

14. Tierney, J. E. et al. Tropical sea-surface temperatures for the past four centuries reconstructed from coral archives. Paleoceanography 30, 226-252 (2015).

15. McGregor, H. V. et al. Robust global ocean cooling trend for the pre-industrial Common Era. Nat. Geosci. 8, 671-677 (2015).

16. McKay, N. P. \& Kaufman, D. S. An extended Arctic proxy temperature database for the past 2,000 years. Sci. Data 1, 140026 (2014).

17. Schmidt, G. A. et al. Climate forcing reconstructions for use in PMIP simulations of the last millennium (v1.0). Geosci. Model Dev. 4, 33-45 (2011).

18. Crespin, E., Goosse, H., Fichefet, T., Mairesse, A. \& Sallaz-Damaz, Y. Arctic climate over the past millennium: annual and seasonal responses to external forcings. Holocene 23, 321-329 (2013).

19. Otto-Bliesner, B. L. et al. Climate variability and change since $850 \mathrm{CE}$ : an ensemble approach with the Community Earth System Model (CESM). Bull. Am. Meteorol. Soc. 97, 735-754 (2015).

20. Schurer, A. P., Tett, S. F. B. \& Hegerl, G. C. Small influence of solar variability on climate over the past millennium. Nat. Geosci. 7, 104-108 (2014).

21. Phipps, S. J. et al. Paleoclimate data-model comparison and the role of climate forcings over the past 1500 years. J. Clim. 26, 6915-6936 (2013)

22. Sigl, M. et al. Timing and climate forcing of volcanic eruptions for the past 2,500 years. Nature 523, 543-549 (2015).

23. Abram, N. J. et al. Acceleration of snow melt in an Antarctic Peninsula ice core during the twentieth century. Nat. Geosci. 6, 404-411 (2013).

24. Hannig, J. \& Marron, J. S. Advanced distribution theory for SiZer. J. Am. Stat. Assoc. 101, 484-499 (2006).

25. Steig, E. J. et al. Warming of the Antarctic ice-sheet surface since the 1957 International Geophysical Year. Nature 457, 459-462 (2009).

26. Jones, J. M. et al. Assessing recent trends in high-latitude Southern Hemisphere surface climate. Nat. Clim. Chang. (in the press).

27. Screen, J. A. \& Simmonds, I. The central role of diminishing sea ice in recent Arctic temperature amplification. Nature 464, 1334-1337 (2010).

28. Hawkins, E. \& Sutton, R. Time of emergence of climate signals. Geophys. Res. Lett. 39, L01702 (2012)

29. Diffenbaugh, N. \& Scherer, M. Observational and model evidence of global emergence of permanent, unprecedented heat in the 20th and 21 st centuries. Clim. Change 107, 615-624 (2011).

30. Mora, C. et al. The projected timing of climate departure from recent variability. Nature 502, 183-187 (2013).

31. Lyu, K., Zhang, X., Church, J. A., Slangen, A. B. A. \& Hu, J. Time of emergence for regional sea-level change. Nat. Clim. Chang. 4, 1006-1010 (2014).

32. PAGES 2k-PMIP3 group. Continental-scale temperature variability in PMIP3 simulations and PAGES $2 \mathrm{k}$ regional temperature reconstructions over the past millennium. Clim. Past 11, 1673-1699 (2015).
33. Bracegirdle, T. J., Stephenson, D. B., Turner, J. \& Phillips, T. The importance of sea ice area biases in 21st century multimodel projections of Antarctic temperature and precipitation. Geophys. Res. Lett. 42, 10832-10839 (2015).

34. Schurer, A. P., Hegerl, G. C. \& Obrochta, S. P. Determining the likelihood of pauses and surges in global warming. Geophys. Res. Lett. 42, 5974-5982 (2015).

35. Stott, P. A. et al. Detection and attribution of climate change: a regional perspective. WIREs Clim. Chang. 1, 192-211 (2010).

36. Bakun, A. Global climate change and intensification of coastal ocean upwelling. Science 247, 198-201 (1990).

37. McGregor, H. V., Dima, M., Fischer, H. W. \& Mulitza, S. Rapid 20th-century increase in coastal upwelling off northwest Africa. Science 315, 637-639 (2007).

38. Narayan, N., Paul, A., Mulitza, S. \& Schulz, M. Trends in coastal upwelling intensity during the late 20th century. Ocean Sci. 6, 815-823 (2010).

39. Liu, Z., Vavrus, S., He, F., Wen, N. \& Zhong, Y. Rethinking tropical ocean response to global warming: the enhanced equatorial warming. J. Clim. 18 4684-4700 (2005)

40. Xie, S.-P. et al. Global warming pattern formation: sea surface temperature and rainfall. J. Clim. 23, 966-986 (2010)

41. Collins, M. et al. The impact of global warming on the tropical Pacific Ocean and El Niño. Nat. Geosci. 3, 391-397 (2010).

42. Ji, F., Wu, Z., Huang, J. \& Chassignet, E. P. Evolution of land surface ai temperature trend. Nat. Clim. Chang. 4, 462-466 (2014).

43. Brönnimann, S. et al. Southward shift of the northern tropical belt from 1945 to 1980. Nat. Geosci. 8, 969-974 (2015).

44. Seidel, D. J., Fu, Q., Randel, W. J. \& Reichler, T. J. Widening of the tropical belt in a changing climate. Nat. Geosci. 1, 21-24 (2008).

45. Hu, Y., Zhou, C. \& Liu, J. Observational evidence for poleward expansion of the Hadley circulation. Adv. Atmos. Sci. 28, 33-44 (2011)

46. Staten, P. W., Rutz, J. J., Reichler, T. \& Lu, J. Breaking down the tropospheric circulation response by forcing. Clim. Dyn. 39, 2361-2375 (2012).

47. Armour, K. C., Marshall, J., Scott, J. R., Donohoe, A. \& Newsom, E. R. Southern Ocean warming delayed by circumpolar upwelling and equatorward transport. Nat. Geosci. 9, 549-554 (2016).

48. Abram, N. J. et al. Evolution of the Southern Annular Mode during the past millennium. Nat. Clim. Chang. 4, 564-569 (2014).

49. Rahmstorf, S. et al. Exceptional twentieth-century slowdown in Atlantic Ocean overturning circulation. Nat. Clim. Chang. 5, 475-480 (2015).

50. Ricke, K. L. \& Caldeira, K. Maximum warming occurs about one decade after a carbon dioxide emission. Environ. Res. Lett. 9, 124002 (2014).

\section{Supplementary Information is available in the online version of the paper}

Acknowledgements We thank the many scientists who made their published palaeoclimate datasets available via public data repositories. This work developed out of the PAGES (Past Global Changes) Ocean2k working group; we are grateful to K. Anchukaitis, H. Wu, C. Giry, D. Oppo and V. Ersek for their contributions to the Ocean $2 \mathrm{k}$ syntheses, to the more than 75 volunteers who constructed the Ocean $2 \mathrm{k}$ phase 1 metadatabase ${ }^{14,15}$, and to K. Anchukaitis and V. Trouet for discussions. We thank P. Petrelli, F. Klein and A. Schurer for assistance in obtaining model datasets, and K. McGregor for editorial assistance. We acknowledge support from PAGES funded by the US and Swiss National Science Foundations (NSF) and NOAA, and thank T. Kiefer, M.-F. Loutre and the PAGES $2 \mathrm{k}$ Network Coordinators for organizational support. We acknowledge the World Climate Research Programme's Working Group on Coupled Modelling, which is responsible for CMIP, and we thank the climate modelling groups for producing and making available their model output. The US Department of Energy's Program for Climate Model Diagnosis and Intercomparison provides coordinating support for CMIP and led development of software infrastructure in partnership with the Global Organization for Earth System Science Portals. N.J.A. is supported by an Australian Research Council (ARC) QEll fellowship awarded under DP110101161 and this work contributes to ARC Discovery Project DP140102059 (N.J.A., M.A.J.C.) and the ARC Centre of Excellence for Climate System Science (N.J.A., S.J.P., J.G.). H.V.M. is supported by ARC Future Fellowship FT140100286 and acknowledges funding from ARC Discovery Project DP1092945 (H.M.V., S.J.P.). We acknowledge fellowship support from a CSIC-Ramón y Cajal post-doctoral programme RYC-201314073 (B.M.), a Clare Hall College Cambridge Shackleton Fellowship (B.M.) and an ARC DECRA fellowship DE130100668 (J.G.). We acknowledge research support from US NSF grant OCE1536249 (M.N.E.), the ARC Special Research Initiative for the Antarctic Gateway Partnership (Project ID SR140300001; S.J.P.), Red CONSOLIDER GRACCIE CTM2014-59111-REDC (B.M.), Swiss NSF grant PZOOP2_154802 (R.N.), the Danish Council for Independent Research, Natural Science OCEANHEAT project 12-126709/FNU (M.-S.S.), the National Natural Science Foundation of China (41273083; K.S.) and Shanghai Fund (2013SH012; K.S.). This is University of Maryland Center for Environmental Science contribution 5206.

Author Contributions N.J.A. designed the study with input from H.V.M., J.E.T., M.N.E., N.P.M. and D.S.K. The palaeoclimate data and model analysis was led by N.J.A. with assistance provided by R.N., K.T., B.M., H.G., S.J.P. and E.J.S.; R.N. and J.G. produced the terrestrial Australasia 2k reconstruction; N.J.A., J.E.T., M.N.E., K.H.K., C.P.S. and J.Z. contributed expertise on the high-resolution marine database and reconstructions; H.V.M., M.N.E., B.M., K.T., G.L., J.A.A., P.G.M. M.-S.S., M.-A.S., K.S. and H.L.F. contributed expertise on the moderate-resolution 


\section{RESEARCH ARTICLE}

marine database; H.G. S.J.P. and N.J.A. contributed expertise on climate model output, and N.P.M., D.S.K., R.N., E.J.S., J.G., M.A.J.C. and L.v.G. contributed expertise on the terrestrial databases and reconstructions. All authors contributed to discussions that shaped the study and the manuscript. N.J.A. led the writing with contributions from all authors.

Author Information The data and code needed to reproduce the results are available at the World Data Service for Paleoclimatology (http://www.ncdc.noaa. gov/paleo/study/20083). Reprints and permissions information is available at www.nature.com/reprints. The authors declare no competing financial interests. Readers are welcome to comment on the online version of the paper. Correspondence and requests for materials should be addressed to N.J.A. (nerilie.abram@anu.edu.au).

Reviewer Information Nature thanks Z. Liu, T. Watanabe and the other anonymous reviewer(s) for their contribution to the peer review of this work.

\section{PAGES 2k Consortium}

Kaustubh Thirumalai ${ }^{8}$, Belen Martrat 9,10 , Hugues Goosse ${ }^{11}$

Steven J. Phipps ${ }^{12,13,14}$, Eric J. Steig 15,16, K. Halimeda Kilbourne ${ }^{17}$

Casey P. Saenger ${ }^{18}$, Jens Zinke ${ }^{19,20,21}$, Guillaume Leduc ${ }^{22}$, Jason A.. Addison ${ }^{23}$ P. Graham Mortyn ${ }^{24}$. Marit-Solveig Seidenkrantz ${ }^{25}$, Marie-Alexandrine Sicre ${ }^{26}$, Kandasamy Selvaraj ${ }^{27}$, Helena L. Filipsson ${ }^{28}$, Raphael Neukom ${ }^{29}$, Joelle Gergis ${ }^{30,31}$, Mark A.J. Curran ${ }^{32}$ \& Lucien von Gunten ${ }^{33}$

${ }^{8}$ Institute for Geophysics, Jackson School of Geosciences, University of Texas, Austin, Texas 78758, USA. ${ }^{9}$ Department of Environmental Chemistry, Institute of Environmental Assessment and Water Research (IDÆA), Spanish Council for Scientific Research (CSIC), 08034 Barcelona, Spain. ${ }^{10}$ Department of Earth Sciences, Downing Street, University of Cambridge, Cambridge CB2 3EQ, UK. ${ }^{11}$ Earth and Life Institute, Université de Louvain, Place pasteur 3, 1348
Louvain-la-Neuve, Belgium. ${ }^{12}$ ARC Centre of Excellence for Climate System Science, University of New South Wales, Sydney, New South Wales 2052, Australia. ${ }^{13}$ Climate Change Research Centre, University of New South Wales, Sydney, New South Wales 2052, Australia. ${ }^{14}$ Institute for Marine and Antarctic Studies, University of Tasmania, Hobart, Tasmania 7001, Australia. ${ }^{15}$ School of Geosciences, University of Edinburgh, Edinburgh EH9 3FE, UK. ${ }^{16}$ Department of Earth and Space Sciences, University of Washington, Seattle, Washington 98195 USA.

${ }^{17}$ Chesapeake Biological Laboratory, University of Maryland Center for Environmental Science, Solomons, Maryland 20688, USA. ${ }^{18} \mathrm{~J}$ oint Institute for the Study of the Atmosphere and Ocean, University of Washington, Seattle, Washington, USA. ${ }^{19}$ Curtin University of Technology, Department of Environment and Agriculture, Bentley, Western Australia 6845, Australia. ${ }^{20}$ Australian Institute of Marine Science, 39 Fairway, Nedlands, Western Australia 6009 , Australia. ${ }^{21}$ Institute of Geological Sciences, Section Palaeontology, Freie Universität Berlin, Malteserstrasse 74-100, 12249 Berlin, Germany. ${ }^{22}$ Aix Marseille Université, CNRS, IRD, Coll France, CEREGE, 13545 Aix-en-Provence, France. ${ }^{23}$ US Geological Survey, 345 Middlefield Road, MS 910, Menlo Park, California 94025, USA. ${ }^{24}$ Universitat Autonoma de Barcelona, Institute of Environmental Science and Technology (ICTA) and Department of Geography, Bellaterra 08193, Spain. ${ }^{25}$ Centre for Past Climate Studies and Arctic Research Centre, Department of Geoscience, Aarhus University, Hoegh-Guldbergs Gade 2, DK-8000 Aarhus C, Denmark. ${ }^{26}$ Sorbonne Universités (UPMC, Université Paris 06)-CNRS-IRD-MNHN, LOCEAN Laboratory, 4 place Jussieu, F-75005 Paris, France. ${ }^{27}$ State Key Laboratory of Marine Environmental Science and Department of Geological Oceanography, Xiamen University, Xiamen 361102, China. ${ }^{28}$ Department of Geology, Lund University, Sölvegatan 12, SE-223 62 Lund, Sweden. ${ }^{29}$ Oeschger Centre for Climate Change Research and Institute of Geography, University of Bern, 3012 Bern, Switzerland. ${ }^{30}$ School of Earth Sciences, University of Melbourne, Melbourne, Victoria 3010, Australia. ${ }^{31}$ ARC Centre of Excellence for Climate System Science, University of Melbourne, Melbourne, Victoria 3010, Australia. ${ }^{32}$ Australian Antarctic Division and Antarctic Climate and Ecosystems Cooperative Research Centre, Hobart, Tasmania 7000, Australia. ${ }^{33}$ PAGES International Project Office, Falkenplatz 16, 3012 Bern, Switzerland. 


\section{METHODS}

Palaeoclimate data. We use the newly developed SST reconstructions and palaeoclimate databases of the PAGES Ocean2k working group. For full details of the data selection criteria and in-depth discussions of the marine datasets and reconstructions, see refs 14 and 15 .

The high-resolution (annual or better) component of the Ocean $2 k$ dataset consists of 57 coral records (including multiple sensors for some records; Extended Data Table 1), which were used to reconstruct regional mean SST histories for different sectors of the tropical oceans ${ }^{14}$. The SST reconstructions for the tropical Indian, western Pacific and western Atlantic regions are statistically robust over most of the past 400 years ${ }^{14}$. The same reconstruction method applied to the tropical eastern Pacific region yielded poorer statistics and a twentieth-century SST trend that is stronger than suggested by instrumental records. This was attributed to nonlinear hydrologic effects in the eastern tropical Pacific ${ }^{14}$; hence, we exclude this regional reconstruction from the current study. We use the 'best' reconstruction for each region, as identified in ref. 14 on the basis of validation statistics from the ensemble of reconstructions produced. From the Ocean $2 \mathrm{k}$ low-resolution database ${ }^{15}$, we use a subset of 21 marine records that are suitable for the recent temperature trend analysis carried out in this study (Extended Data Fig. 7a). These 21 records meet additional criteria of having strong chronological control through ${ }^{210} \mathrm{~Pb}$ profiling or counting of annual sediment layers or coral growth bands, as well as an average sample resolution of 25 years or better; we refer to these as moderate-resolution records. The sense of the proxy-temperature response of the high- and moderate-resolution ocean palaeoclimate records is based on known physical relationships for the incorporation of geochemical and biological tracers into these records or on individually assessed and published temperature-growth relationships.

We compare the ocean records to the continental-scale temperature reconstructions and palaeoclimate databases developed in phase 1 of the PAGES $2 \mathrm{k}$ project $^{4}$, including the updated Arctic v1.1.1 reconstruction and database ${ }^{16}$. For the North America region we use the tree-ring-based reconstruction, which has decadal resolution, rather than the lower-resolution pollen-derived temperature reconstruction. To avoid record duplication, all marine records were removed from the PAGES $2 \mathrm{k}$ continental database before site-level trend analysis. We also exclude the four instrumental records in the South American $2 \mathrm{k}$ database from our site-level data assessment so that all information is derived solely from palaeoclimate archives. At the level of regional temperature reconstructions, a small degree of overlap exists in the contributing data used for some of the previously published reconstructions. Specifically, 9 of the 28 records used for the Australasia $2 \mathrm{k}$ temperature reconstruction are also used for the tropical western Pacific SST reconstruction, and 1 is used for the tropical Indian Ocean SST reconstruction. To avoid any bias introduced by data overlap, we use a terrestrial-only Australasia $2 \mathrm{k}$ reconstruction that was produced using the same methodology as the original reconstruction ${ }^{4}$, but excludes any of the marine geochemistry records that are used in the Ocean $2 \mathrm{k}$ high-resolution reconstructions. Details of this terrestrialonly reconstruction, and the reconstruction data and statistics, accompany this paper as Supplementary Data 1. The terrestrial-only reconstruction demonstrates close agreement with the original Australasia $2 \mathrm{k}$ reconstruction and none of the interpretations presented here is altered by using the original reconstruction instead of the terrestrial-only version.

Matlab data structures containing the site-level proxy data and regional reconstructions used in this study are archived with the National Centers for Environmental Information (NCEI) World Data Service for Paleoclimatology at http://www.ncdc.noaa.gov/paleo/study/20083.

Palaeoclimate data analysis and uncertainties. The analyses performed in this study use annually resolved, unsmoothed input data. For the moderately resolved marine records (resolution given in Extended Data Fig. 7a) and the North America reconstruction (decadal resolution), pseudo-annual data was produced by performing a nearest-neighbour interpolation to produce stepped datasets that continued values across the entire sampling interval that they represent. Chronological uncertainty in the palaeoclimate records and reconstructions is extremely low for the industrial era. Annual layer chronologies would be expected to be known to within $\pm 2-3$ yr back to AD 1800 , using conservative estimates and not taking into account the 1815 Tambora eruption that left an unambiguous fixed-time marker in many palaeoclimate archives. Therefore, chronological uncertainty in the industrial era is well within the level of interpretability of our estimates for the onset of sustained, significant warming based on the change-point detection method (see Methods section 'Change-point method testing').

The area weightings used to calculate the average tropical ocean temperature histories in Fig. 1d were based on the surface area of the target reconstruction regions on an Earth ellipsoid. These areas are: Indian Ocean, $25.5 \times 10^{6} \mathrm{~km}^{2}$ western Pacific, $26.9 \times 10^{6} \mathrm{~km}^{2}$; western Atlantic, $5.1 \times 10^{6} \mathrm{~km}^{2}$. The areas of the terrestrial reconstruction regions ${ }^{4}$ (Fig. 1c) are: Arctic, $34.4 \times 10^{6} \mathrm{~km}^{2}$; Europe $13.0 \times 10^{6} \mathrm{~km}^{2}$; Asia, $31.1 \times 10^{6} \mathrm{~km}^{2}$; North America, $12.5 \times 10^{6} \mathrm{~km}^{2}$; Australasia, $37.9 \times 10^{6} \mathrm{~km}^{2}$; South America, $20.0 \times 10^{6} \mathrm{~km}^{2}$; Antarctica, $34.4 \times 10^{6} \mathrm{~km}^{2}$.

The seasonality of the temperature signal captured by the reconstructions differs between regions, owing to the availability of site-level palaeoclimate records in each region, some of which capture climate information related to only a specific season (for example, a summer growing season for trees). Detailed discussion on seasonality can be found in refs 4,14 and 15 . To summarize: the tropical ocean reconstructions represent April-March (tropical year) annual averages; the Arctic, North America and Antarctic reconstructions represent annual averages the Australasia reconstruction represents a September-February half-year (warm season) average; and the Europe, Asia and South America reconstructions represent local summer averages. We do not expect the seasonal differences between the regional reconstructions to affect our interpretations of the onset of sustained, significant warming between different regions. Change-point analysis of climate model simulations produces near-identical regional warming onsets when data are compiled as annual averages across all regions, and as season-specific averages that match the reported seasonality for each corresponding palaeoclimate reconstruction (Extended Data Fig. 4).

The effect that uncertainty in the regional temperature reconstructions may have on estimates of the onset of industrial-era warming was assessed using reconstruction ensembles (Extended Data Fig. 1a). Reconstruction ensembles are available for South America, Australasia and the three tropical ocean regions, and were calculated as part of the original reconstruction process by using different methodological choices based on the proxy network, the temperature calibration interval and/or target dataset. We also extend this analysis to reconstruction ensembles available for Northern Hemisphere ${ }^{3}$ and Southern Hemisphere ${ }^{5}$ average temperature as an additional test of the apparent Southern Hemisphere delay in the onset of industrial-era warming (Extended Data Fig. 1a, Supplementary Fig. 1) Uncertainty in the onset of industrial-era warming related to reconstruction uncertainty has a $5 \%-95 \%$ range of within $-3 \mathrm{yr}$ to $+25 \mathrm{yr}$ for the three tropical ocean regions (which each have an average $\pm 2 \sigma$ range across reconstruction members of approximately $0.1{ }^{\circ} \mathrm{C}$ during the nineteenth and twentieth centuries). The Australasia ensembles have an average $\pm 2 \sigma$ range of $0.4^{\circ} \mathrm{C}$ during the nineteenth and twentieth centuries, and there is a $-35 \mathrm{yr}$ to $+46 \mathrm{yr}$ range $(5 \%-95 \%)$ in onset estimates determined across this ensemble. The South America ensembles have an average $\pm 2 \sigma$ range of $0.6^{\circ} \mathrm{C}$ during the nineteenth and twentieth centuries, and $\mathrm{a}-16 \mathrm{yr}$ to $+31 \mathrm{yr}$ range $(5 \%-95 \%)$ in the onset of industrial-era warming (Extended Data Fig. 1a).

As a first-order estimate, the ranges of onset timings obtained from regions for which reconstruction ensembles are available may provide guidance on how reconstruction uncertainty affects other regions. The regional reconstructions for the Arctic and Europe have a similar magnitude of uncertainty during the nineteenth and twentieth centuries to the South America reconstruction (average $\pm 2 \sigma$ of approximately $0.6^{\circ} \mathrm{C}$ ). Therefore, uncertainty in the onset of industrial-era warming related to regional reconstruction quality may be similar between these regions. Reconstruction uncertainty is higher for Asia (approximately $0.9^{\circ} \mathrm{C}$ for \pm 2 root-mean-square error) and Antarctica (approximately $1.2^{\circ} \mathrm{C}$ for \pm 2 standard error), and so we may expect a larger uncertainty range in onset estimates related to reconstruction quality for these regions. Reconstruction uncertainty for North America is based on decadal-resolution data, and so is not directly comparable to the annual resolution of the other regional reconstructions.

Sample size. No statistical methods were used to predetermine sample size.

Model output. We compare the regional palaeoclimate reconstructions to a multi-model ensemble of transient last-millennium simulations from AD 850 to AD $1850^{51}$ (Extended Data Table 2), completed as part of the Fifth Coupled Model Intercomparison Project (CMIP5). Historical simulations from the same ensemble were used to extend the model output from AD 1850 to AD 2005. The CMIP5 last-millennium and historical experiments use transient radiative forcings that include orbital, solar, volcanic, greenhouse and ozone parameters, as well as landuse changes ${ }^{17,52}$. All data were accessed from the Earth System Grid Federation, with the exception of the historical portions of the HadCM3 simulation (provided by A. Schurer) and the FGOALS-s2 simulation (provided by T. Zhou and W. Man).

Multiple simulations of the last-millennium run with LOVECLIM ${ }^{18}$ were used to examine climate responses to single radiative forcing scenarios (three ensemble members each) and to assess intra-model variability in full forcing simulations (ten ensemble members). We also examine multiple last-millennium simulations of the CSIRO Mk3L coupled climate model run with progressive addition of radiative forcings (three ensemble members each) ${ }^{21}$. The climate response to greenhouse gas forcing alone was further assessed using single forcing experiments of the $\mathrm{HadCM}^{20}$ (four ensemble members) and NCAR CESM ${ }^{19}$ (three ensemble members) models. 
For each of the models we examine surface air temperature (tas field in CMIP5 output files) averaged over the PAGES $2 \mathrm{k}$ continental palaeoclimate reconstruction regions, and sea surface temperature (tos field in CMIP5 output files) averaged over the PAGES Ocean $2 \mathrm{k}$ tropical ocean reconstruction regions. Monthly resolution model output was used to generate annual or season-specific averages that correspond to each palaeoclimate reconstruction target region. Because we use the simulations to examine change-points rather than the magnitude of trends, we do not apply any drift corrections to the model output. Change-point analysis was performed on individual model runs and then compiled (Fig. 3, Supplementary Fig. 2, Extended Data Fig. 8), rather than on ensemble averages, to avoid loss of internal variability in the model data.

Matlab data structures containing the model output (compiled as regional time series with annual-average and season-specific resolution) used in this study are archived with the NCEI World Data Service for Paleoclimatology at http://www. ncdc.noaa.gov/paleo/study/20083.

Change-point analysis method. We analyse the trends in the PAGES $2 \mathrm{k}$ continental and tropical ocean temperature reconstructions (Fig. 2a, Extended Data Fig. 1a), in the site-level terrestrial and marine palaeoclimate databases (Fig. 4, Extended Data Figs 6, 7) and in model simulations (Fig. 3, Extended Data Figs 2, 8, Supplementary Figs 2, 3) using the SiZer (SIgnificant ZERo crossings of derivatives) $\operatorname{method}^{24}$. SiZer determines the sign and significance of trends in time series data across different levels of smoothing using a Gaussian kernel filter. Following the method used in refs 14 and 23, we assess climate change-points from SiZer output by determining the median year of initiation for the most recent significant $(P<0.1)$ and sustained trends across smoothing bandwidths spanning all integer years in the range $15-50 \mathrm{yr}$. This range of smoothing levels is designed to reduce the influence of interannual-to-decadal climate variability on the detection of a sustained trend, while avoiding shifting the true change-point time if the smoothing window is too long. We assess trends in the time series since AD 1500, and the onset of the most recent significant trend is classified only if the sign of the trend persists through to the most recent end of the record (that is, a sustained trend). Extended Data Fig. 2a shows the SiZer data used to assess the median initiation point for recent significant warming trends across the continents and tropical oceans in palaeoclimate reconstructions (Fig. 2a). Supplementary Fig. 1 shows the SiZer data for multi-model palaeoclimate simulations (Fig. 3a).

Change-point method testing. Change-points determined by the SiZer method were tested on a set of synthetic time series with known warming onset (Extended Data Fig. 3). We also compare SiZer estimates for the synthetic warming onset with change-points determined using linear change-point methods ${ }^{53,54}$. The synthetic time series were designed to test the performance of change-point detection methods across different forms of long-term trends, in the presence of volcanic-style cooling events, and for varying magnitudes and redness (lag-1 autocorrelation) of variability superimposed upon the trend. Each test was carried out across 1,000-member ensembles to generate a distribution of change-point estimates for each method.

Linear change-point detection methods best capture the change-point in synthetic time series when the long-term trend is derived from two straight lines (Extended Data Fig. 3a, series i, ii). However, the SiZer method is more adaptable than linear change-point methods in detecting the true change-point in time series in which the long-term trend is a curve rather than a straight line (Extended Data Fig. 3a, series iii). This is expected to be advantageous for detecting the initial thermodynamic response to increases in atmospheric greenhouse gas levels, which have an accelerating trajectory during the industrial era (Fig. 3d). Previous research has concluded that, despite the complexity of the climate system, there is a near-linear relationship between global radiative forcing changes and the climate response ${ }^{10,55}$. Hence, we would expect industrial era climate trends to be better approximated by a curve than by a simple straight line.

The addition of synthetic volcanic-style cooling events at the time of, and before, the change-point in synthetic series causes only small deviations in SiZer estimates of the climate change-point away from the true synthetic change-point (Extended Data Fig. 3a, series iv-vi). In our tests with a curved (accelerating) warming trend and volcanic-style cooling events centred at $0 \mathrm{yr},-25 \mathrm{yr}$ and $-50 \mathrm{yr}$ relative to the onset of the warming trend, the SiZer method returns median times for the warming onset at $-1 \mathrm{yr},-9 \mathrm{yr}$ and $-13 \mathrm{yr}$, respectively. This gives us confidence that large volcanic eruptions during the early nineteenth century are not likely to have substantially skewed the detection of the onset of industrial-era warming trends assessed using the SiZer method.

Finally, we test the sensitivity of change-point detection methods to the addition of varying climate variability (autoregressive $\mathrm{AR}(1)$ noise) superimposed on the same long-term warming trend. As the magnitude of climate variability increases, the detection of change-points becomes progressively later using the SiZer method (Extended Data Fig. 3b). As a result, climate time series from regions with large interannual-to-multi-decadal variability may have delayed detection of the onset of industrial-era warming relative to regions with small variability, unless the magnitude of the underlying warming trend is also larger in these regions. In our testing, different levels of lag- 1 autocorrelation for the $\mathrm{AR}(1)$ noise added to an underlying trend does not alter the median estimate for the onset of warming; however, the range of onset estimates about this median becomes greater as autocorrelation increases (Extended Data Fig. 3c).

Across all of the tests examined here, the linear intersection and Bayesian change-point detection methods produce much wider ranges of warming onset estimates than those produced using the SiZer method on the same synthetic ensembles (Extended Data Fig. 3a-c). The linear methods are also less able to detect change-points for trends that are not simple linear functions. On the basis of our change-point method testing, we use the SiZer method in this study, because it appears to be most adaptable and stable for dealing with the climate changes that characterize industrial-era warming.

We apply our method testing to assess the range of uncertainty in estimates of the onset of regional warming related to the SiZer change-point detection method (Extended Data Fig. 1b). This is carried out using an accelerating warming trend upon which $\mathrm{AR}(1)$ noise is added that has the same lag-1 autocorrelation and trend-to-variability characteristics as the regional reconstructions. These parameters are estimated by calculating characteristics of residuals about the 15-yr filters (as in Fig. 2a) of the regional reconstructions. Uncertainty in onset estimates related to the SiZer method is small, typically better than \pm 25 yr (5\%-95\%). Exceptions are Antarctica, for which the small trend relative to variability does not allow for the detection of significant trends, and Asia, for which strong lag- 1 autocorrelation leads to uncertainty in the lower (5\%) bound for the onset of warming (Extended Data Fig. 1b).

Emergence testing. We use the regional temperature reconstructions to determine the extent to which industrial-era warming has caused regional climates to emerge above the level of pre-industrial variability. We choose the interval AD 1622-1799 as the climate baseline to test emergence against. The starting point (AD 1622) represents the earliest year for which temperature reconstructions are available for all of the terrestrial and marine regions examined in this study. The end year (AD 1799) was chosen as a time well before the onset of industrial-era warming in any of the regional reconstructions (Table 1). It is also before strong volcanic cooling events associated with the 1809 Unknown and 1815 Tambora eruptions, which could skew the reference period towards cooler states.

Time of emergence is detected when a climate change signal emerges above a defined noise threshold ${ }^{28}$. Here we use a threshold of $2 \sigma$ of interannual variability above the mean of the reference interval (Fig. 2c). We smooth the reconstruction using filters with widths of $15-50 \mathrm{yr}$ (the same as for our change-point assessments) and calculate the median time when the climate signal (smoothed reconstructions) emerges and stays above the noise threshold. The emergence year is quite insensitive to the level of smoothing we apply to the climate signal across the 15-50-yr filter widths, with the 5\%-95\% range of emergence estimates being between only $1 \mathrm{yr}$ and $8 \mathrm{yr}$ for the regional reconstructions for which climate emergence is found to occur.

A difference between our climate emergence assessment and previously published time-of-emergence studies is that the palaeoclimate reconstructions allow us to assess climate emergence using a long baseline interval that occurs entirely before the onset of industrial-era warming. Our results demonstrate that, in some regions, industrial-era warming has already caused climate to emerge above the range of natural variability in the AD 1622-1799 reference interval (Table 1). We test the sensitivity of this result to the choice of reference interval and find that all tested reference intervals before the onset of industrial-era warming result in similar regional emergence patterns and timings, whereas reference periods that include parts of the industrial-era warming signal result in later estimates for the time of emergence. For example, in the Arctic reconstruction, time-of-emergence estimates based on different reference periods are: AD 1947 (AD 1500-1799 reference), AD 1930 (AD 1600-1799 reference), AD 1930 (AD 1622-1799 reference; Table 1), AD 1938 (AD 1700-1799 reference), AD 1960 (AD 1800-1899 reference) and $\mathrm{AD} 1978$ ( $\mathrm{AD} 1850-1899$ reference). The overlapping interval of the regional reconstructions that we use for our time-of-emergence reference (AD 1622-1799) occurs during the time of coolest conditions during the past 2,000 years ${ }^{4,15}$. Using longer palaeoclimate reference intervals that incorporate earlier, warm intervals of the past 2,000 years will alter time-of-emergence results, but it is not currently possible to perform this assessment consistently between regions, owing to the length limitations of currently available tropical ocean temperature reconstructions.

Instrumental data. We plot temperature trends from gridded instrumental datasets in Fig. 1. The surface air temperature datasets are from the Climate Research Unit (CRU) TS3.22 product ${ }^{56}$, or the ERAI-f product ${ }^{57}$ for surface air temperature over Antarctica, and the sea surface temperature datasets are from 
the HadiSST product ${ }^{58}$. The $\mathrm{CO}_{2}$-equivalent record shown in Fig. $3 \mathrm{~d}$ is derived from ref. 59.

Code availability. Matlab code for assessing the onset (and sign) of industrial-era climate trends using the SiZer method is archived with the NCEI World Data Service for Paleoclimatology at http://www.ncdc.noaa.gov/paleo/study/20083. These files include the original SiZer package $\mathrm{e}^{24}$ obtained from http://www.unc. edu/ marron/marron_software.html, and additional code to assess the onset of sustained, significant temperature trends in annually resolved climate records.

51. Taylor, K. E., Stouffer, R. J. \& Meehl, G. A. An overview of CMIP5 and the experiment design. Bull. Am. Meteorol. Soc. 93, 485-498 (2012).

52. Schmidt, G. A. et al. Climate forcing reconstructions for use in PMIP simulations of the last millennium (v1.1). Geosci. Model Dev. 5, 185-191 (2012).

53. Mudelsee, M. Break function regression. Eur. Phys. J. Spec. Top. 174, 49-63 (2009).

54. Ruggieri, E. A Bayesian approach to detecting change points in climatic records. Int. J. Climatol. 33, 520-528 (2013).

55. Crowley, T. J. Causes of climate change over the past 1000 years. Science 289, 270-277 (2000)

56. Harris, I., Jones, P. D., Osborn, T. J. \& Lister, D. H. Updated high-resolution grids of monthly climatic observations - the CRU TS3.10 dataset. Int. J. Climatol. 34 623-642 (2014).

57. Nicolas, J. P. \& Bromwich, D. H. New reconstruction of Antarctic near-surface temperatures: multidecadal trends and reliability of global reanalyses. J. Clim. 27, 8070-8093 (2014)

58. Rayner, N. A. et al. Global analyses of sea surface temperature, sea ice, and night marine air temperature since the late nineteenth century. J. Geophys. Res. Atmos. 108, 4407 (2003).

59. MacFarling Meure, C. et al. Law Dome $\mathrm{CO}_{2}, \mathrm{CH}_{4}$ and $\mathrm{N}_{2} \mathrm{O}$ ice core records extended to 2000 years BP. Geophys. Res. Lett. 33, L14810 (2006).

60. Oppo, D. W., Rosenthal, Y. \& Linsley, B. K. 2,000-year-long temperature and hydrology reconstructions from the Indo-Pacific warm pool. Nature $\mathbf{4 6 0}$, 1113-1116 (2009).

61. Pahnke, K., Sachs, J. P., Keigwin, L., Timmermann, A. \& Xie, S.-P. Eastern tropical Pacific hydrologic changes during the past 27,000 years from D/H ratios in alkenones. Paleoceanography 22, PA4214 (2007)

62. Hendy, E. J. et al. Abrupt decrease in tropical Pacific sea surface salinity at end of Little Ice Age. Science 295, 1511-1514 (2002).

63. Hendy, I. L., Dunn, L., Schimmelmann, A. \& Pak, D. K. Resolving varve and radiocarbon chronology differences during the last 2000 years in the Santa Barbara Basin sedimentary record, California. Quat. Int. 310, 155-168 (2013).

64. Schimmelmann, A., Hendy, I. L., Dunn, L., Pak, D. K. \& Lange, C. B. Revised 2000-year chronostratigraphy of partially varved marine sediment in Santa Barbara Basin, California. GFF 135, 258-264 (2013).

65. Zhao, M., Eglinton, G., Read, G. \& Schimmelmann, A. An alkenone $\left(\mathrm{U}_{37} \mathrm{~K}^{\mathrm{K}^{\prime}}\right)$ quasiannual sea surface temperature record (A.D. 1440 to 1940$)$ using varved sediments from the Santa Barbara Basin. Org. Geochem. 31, 903-917 (2000).

66. Gutiérrez, D. et al. Coastal cooling and increased productivity in the main upwelling zone off Peru since the mid-twentieth century. Geophys. Res. Lett. 38, L07603 (2011).

67. Goni, M. A., Thunell, R. C., Woodwort, M. P. \& Müller-Karger, F. E. Changes in wind-driven upwelling during the last three centuries: interocean teleconnections. Geophys. Res. Lett. 33, L15604 (2006).

68. Doose-Rolinski, H., Rogalla, U. R., Scheeder, G., Lückge, A. \& von Rad, U. High-resolution temperature and evaporation changes during the late Holocene in the northeastern Arabian Sea. Paleoceanography 16, 358-367 (2001).

69. Black, D. E. et al. An 8-century tropical Atlantic SST record from the Cariaco Basin: baseline variability, twentieth-century warming, and Atlantic hurricane frequency. Paleoceanography 22, PA4204 (2007).

70. Kuhnert, H. \& Mulitza, S. Multidecadal variability and late medieval cooling of near-coastal sea surface temperatures in the eastern tropical North Atlantic. Paleoceanography 26, PA4224 (2011).

71. Leduc, G., Herbert, C. T., Blanz, T., Martinez, P. \& Schneider, R. Contrasting evolution of sea surface temperature in the Benguela upwelling system under natural and anthropogenic climate forcings. Geophys. Res. Lett. 37, L20705 (2010).

72. Richter, T. O., Peeters, F. J. C. \& van Weering, T. C. E. Late Holocene (0-2.4 ka BP) surface water temperature and salinity variability, Feni Drift, NE Atlantic Ocean. Quat. Sci. Rev. 28, 1941-1955 (2009).

73. Sicre, M. A. et al. Sea surface temperature variability in the subpolar Atlantic over the last two millennia. Paleoceanography 26, PA4218 (2011).

74. Abrantes, F. et al. Shallow-marine sediment cores record climate variability and earthquake activity off Lisbon (Portugal) for the last 2000 years. Quat. Sci. Rev. 24, 2477-2494 (2005).

75. Versteegh, G. J. M., de Leeuw, J. W., Taricco, C. \& Romero, A. Temperature and productivity influences on $\mathrm{U}_{37} \mathrm{~K}^{\prime}$ and their possible relation to solar forcing of the Mediterranean winter. Geochem. Geophys. Geosyst. 8, Q09005 (2007).

76. Moreno, A. et al. The Medieval Climate Anomaly in the Iberian Peninsula reconstructed from marine and lake records. Quat. Sci. Rev. 43, 16-32 (2012).

77. Nieto-Moreno, V. et al. Climate conditions in the westernmost Mediterranean over the last two millennia: an integrated biomarker approach. Org. Geochem. $55,1-10(2013)$
78. Bonnet, S., de Vernal, A., Hillaire-Marcel, C., Radi, T. \& Husum, K. Variability of sea-surface temperature and sea-ice cover in the Fram Strait over the last two millennia. Mar. Micropaleontol. 74, 59-74 (2010).

79. Felis, T. et al. Subtropical coral reveals abrupt early-twentieth-century freshening in the western North Pacific Ocean. Geology 37, 527-530 (2009).

80. Asami, R. et al. Interannual and decadal variability of the western Pacific sea surface condition for the years 1787-2000: reconstruction based on stable isotope record from a Guam coral. J. Geophys. Res. Oceans 110, C05018 (2005)

81. Charles, C. D., Cobb, K., Moore, M. D. \& Fairbanks, R. G. Monsoon-tropical ocean interaction in a network of coral records spanning the 20th century. Mar. Geol. 201, 207-222 (2003)

82. Boiseau, M., Ghil, M. \& Juillet-Leclerc, A. Climatic trends and interdecadal variability from South-Central Pacific coral records. Geophys. Res. Lett. 26, 2881-2884 (1999).

83. Boiseau, M. et al. Atmospheric and oceanic evidences of El Niño-Southern Oscillation events in the south central Pacific Ocean from coral stable isotopic records over the last 137 years. Paleoceanography 13, 671-685 (1998).

84. Tudhope, A. W. et al. Variability in the El Niño-Southern Oscillation through a glacial-interglacial cycle. Science 291, 1511-1517 (2001).

85. Alibert, C. \& Kinsley, L. A 170-year Sr/Ca and Ba/Ca coral record from the Western Pacific Warm Pool: 1. What can we learn from an unusual coral record? J. Geophys. Res. Oceans 113, 04008 (2008)

86. Quinn, T. M., Taylor, F. W. \& Crowley, T. J. Coral-based climate variability in the Western Pacific Warm Pool since 1867. J. Geophys. Res. Oceans 111, C11006 (2006).

87. Linsley, B. K. et al. Tracking the extent of the South Pacific Convergence Zone since the early 1600s. Geochem. Geophys. Geosyst. 7, Q05003 (2006).

88. Quinn, T. M., Crowley, T. J. \& Taylor, F. W. New stable isotope results from a 173-year coral from Espiritu Santo, Vanuatu. Geophys. Res. Lett. 23, 3413-3416 (1996).

89. Gorman, M. K. et al. A coral-based reconstruction of sea surface salinity at Sabine Bank, Vanuatu from 1842 to 2007 CE. Paleoceanography 27, PA3226 (2012).

90. DeLong, K. L., Quinn, T. M., Taylor, F. W., Lin, K. \& Shen, C.-C. Sea surface temperature variability in the southwest tropical Pacific since ad 1649. Nat. Clim. Chang. 2, 799-804 (2012).

91. DeLong, K. L., Quinn, T. M., Taylor, F. W., Shen, C.-C. \& Lin, K. Improving coral-base paleoclimate reconstructions by replicating 350 years of coral Sr/Ca variations. Palaeogeogr. Palaeoclimatol. Palaeoecol. 373, 6-24 (2013).

92. Quinn, T. M. et al. A multicentury stable isotope record from a New Caledonia coral: interannual and decadal sea surface temperature variability in the southwest Pacific since 1657 AD. Paleoceanography 13, 412-426 (1998).

93. Bagnato, S., Linsley, B. K., Howe, S. S. \& Wellington, G. M. Coral oxygen isotope records of interdecadal climate variations in the South Pacific Convergence Zone region. Geochem. Geophys. Geosyst. 6, Q06001 (2005).

94. Kuhnert, H., Patzold, J., Wyrwoll, K. H. \& Wefer, G. Monitoring climate variability over the past 116 years in coral oxygen isotopes from Ningaloo Reef, Western Australia. Int. J. Earth Sci. 88, 725-732 (2000).

95. Druffel, E. R. M. \& Griffin, S. Variability of surface ocean radiocarbon and stable isotopes in the southwestern Pacific. J. Geophys. Res. Oceans 104, 23607-23613 (1999)

96. Wu, H. C., Linsley, B. K., Dassie, E. P., Schiraldi, B. \& deMenocal, P. B. Oceanographic variability in the South Pacific Convergence Zone region over the last 210 years from multi-site coral Sr/Ca records. Geochem. Geophys. Geosyst. 14, 1435-1453 (2013).

97. Linsley, B. K., Ren, L., Dunbar, R. B. \& Howe, S. S. El Niño Southern Oscillation (ENSO) and decadal-scale climate variability at $10^{\circ} \mathrm{N}$ in the eastern Pacific from 1893 to 1994: a coral-based reconstruction from Clipperton Atoll. Paleoceanography 15, 322-335 (2000).

98. Dunbar, R. B., Wellington, G. M., Colgan, M. W. \& Glynn, P. W. Eastern Pacific sea-surface temperature since 1600 A.D.: the $\delta^{18} \mathrm{O}$ record of climate variability in Galápagos Corals. Paleoceanography 9, 291-315 (1994).

99. Urban, F. E., Cole, J. E. \& Overpeck, J. T. Influence of mean climate change on climate variability from a 155-year tropical Pacific coral record. Nature $\mathbf{4 0 7}$, 989-993 (2000).

100. Cole, J. E. \& Fairbanks, R. G. The Southern Oscillation recorded in the $\delta^{18} 0$ of corals from Tarawa Atoll. Paleoceanography 5, 669-683 (1990).

101. Cole, J. E., Fairbanks, R. G. \& Shen, G. T. Recent variability in the Southern Oscillation: isotopic results from a Tarawa Atoll coral. Science 260, 1790-1793 (1993).

102. Guilderson, T. P. \& Schrag, D. P. Reliability of coral isotope records from the Western Pacific Warm Pool: a comparison using age-optimized records. Paleoceanography 14, 457-464 (1999).

103. Linsley, B. K., Dunbar, R. B., Wellington, G. M. \& Mucciarone, D. A. A coral-based reconstruction of Intertropical Convergence Zone variability over Central America since 1707. J. Geophys. Res. Oceans 99, 9977-9994 (1994).

104. Cobb, K. M., Charles, C. D., Cheng, H. \& Edwards, R. L. El Niño/Southern Oscillation and tropical Pacific climate during the last millennium. Nature $\mathbf{4 2 4}$ 271-276 (2003).

105. Nurhati, I. S., Cobb, K. M., Charles, C. D. \& Dunbar, R. B. Late 20th century warming and freshening in the central tropical Pacific. Geophys. Res. Lett. 36, L21606 (2009).

106. Nurhati, I. S., Cobb, K. M. \& Di Lorenzo, E. Decadal-scale SST and salinity variations in the central tropical Pacific: signatures of natural and anthropogenic climate change. J. Clim. 24, 3294-3308 (2011). 
107. Cole, J. E., Dunbar, R. B., McClanahan, T. R. \& Muthiga, N. A. Tropical Pacific forcing of decadal SST variability in the western Indian Ocean over the past two centuries. Science 287, 617-619 (2000).

108. Zinke, J., Pfeiffer, M., Timm, O., Dullo, W. C. \& Brummer, G. J. A. Western Indian Ocean marine and terrestrial records of climate variability: a review and new concepts on land-ocean interactions since AD 1660. Int. J. Earth Sci. 98, 115-133 (2009).

109. Zinke, J. et al. Mayotte coral reveals hydrological changes in the western Indian Ocean between 1881 and 1994. Geophys. Res. Lett. 35, L23707 (2008)

110. Zinke, J., Dullo, W. C., Heiss, G. A. \& Eisenhauer, A. ENSO and Indian Ocean subtropical dipole variability is recorded in a coral record off southwest Madagascar for the period 1659 to 1995. Earth Planet. Sci. Lett. 228, 177-194 (2004)

111. Kuhnert, H. et al. A 200-year coral stable oxygen isotope record from a high-latitude reef off western Australia. Coral Reefs 18, 1-12 (1999).

112. Damassa, T. D., Cole, J. E., Barnett, H. R., Ault, T. R. \& McClanahan, T. R. Enhanced multidecadal climate variability in the seventeenth century from coral isotope records in the western Indian Ocean. Paleoceanography $\mathbf{2 1}$ PA2016 (2006)

113. Abram, N. J., Gagan, M. K., Cole, J. E., Hantoro, W. S. \& Mudelsee, M. Recent intensification of tropical climate variability in the Indian Ocean. Nat. Geosci. 1, 849-853 (2008).

114. Charles, C. D., Hunter, D. E. \& Fairbanks, R. G. Interaction between the ENSO and the Asian monsoon in a coral record of tropical climate. Science 277, 925-928 (1997).

115. Nakamura, N. et al. Mode shift in the Indian Ocean climate under global warming stress. Geophys. Res. Lett. 36, L23708 (2009).

116. Pfeiffer, M., Timm, O., Dullo, W. C. \& Podlech, S. Oceanic forcing of interannual and multidecadal climate variability in the southwestern Indian Ocean: evidence from a 160 year coral isotopic record (La Reunion, $55^{\circ} \mathrm{E}, 21^{\circ} \mathrm{S}$ ) Paleoceanography 19, PA4006 (2004).

117. Heiss, G. A. Coral Reefs in the Red Sea: Growth, Production, and Stable Isotopes. PhD thesis, Christian Albrechts Univ., http://eprints.uni-kiel.de/29262/ (GEOMAR Report 32, GEOMAR Research Center for Marine Geosciences, 1994).

118. Moustafa, Y. Paleoclimatic Reconstructions of the Northern Red Sea During the Holocene Inferred from Stable Isotope Records of Modern and Fossil Corals and Molluscs. PhD thesis, Univ. Bremen., http://elib.suub.uni-bremen.de/ip/ docs/00010274.pdf (2000).
119. Felis, T. et al. A coral oxygen isotope record from the northern Red Sea documenting NAO, ENSO, and North Pacific teleconnections on Middle East climate variability since the year 1750. Paleoceanography 15, 679-694 (2000).

120. Goodkin, N. F., Hughen, K. A., Curry, W. B., Doney, S. C. \& Ostermann, D. R. Sea surface temperature and salinity variability at Bermuda during the end of the Little Ice Age. Paleoceanography 23, PA3203 (2008).

121. Hetzinger, S., Pfeiffer, M., Dullo, W.-C., Garbe-Schoenberg, D. \& Halfar, J. Rapid 20th century warming in the Caribbean and impact of remote forcing on climate in the northern tropical Atlantic as recorded in a Guadeloupe coral. Palaeogeogr. Palaeoclimatol. Palaeoecol. 296, 111-124 (2010).

122. Kilbourne, K. H. et al. Paleoclimate proxy perspective on Caribbean climate since the year 1751: evidence of cooler temperatures and multidecadal variability. Paleoceanography 23, PA3220 (2008).

123. Kuhnert, H., Cruger, T. \& Patzold, J. NAO signature in a Bermuda coral Sr/Ca record. Geochem. Geophys. Geosyst. 6, 004004 (2005).

124. Swart, P. K. et al. The stable oxygen and carbon isotopic record from a coral growing in Florida Bay: a 160 year record of climatic and anthropogenic influence. Palaeogeogr. Palaeoclimatol. Palaeoecol. 123, 219-237 (1996).

125. Swart, P. K., Dodge, R. E. \& Hudson, H. J. A 240-year stable oxygen and carbon isotopic record in a coral from South Florida: implications for the prediction of precipitation in Southern Florida. Palaios 11, 362-375 (1996).

126. Saenger, C., Cohen, A. L., Oppo, D. W., Halley, R. B. \& Carilli, J. E. Surfacetemperature trends and variability in the low-latitude North Atlantic since 1552. Nat. Geosci. 2, 492-495 (2009).

127. Vásquez-Bedoya, L. F., Cohen, A. L., Oppo, D. W. \& Blanchon, P. Corals record persistent multidecadal SST variability in the Atlantic Warm Pool since 1775 AD. Paleoceanography 27, PA3231 (2012).

128. DeLong, K. L. et al. A reconstruction of sea surface temperature variability in the southeastern Gulf of Mexico from 1734 to 2008 C.E. using cross-dated Sr/ Ca records from the coral Siderastrea siderea. Paleoceanography 29, 403-422 (2014).

129. Watanabe, S. et al. MIROC-ESM 2010: model description and basic results of CMIP5-20c3m experiments. Geosci. Model Dev. 4, 845-872 (2011).

130. Bothe, O., Jungclaus, J. H. \& Zanchettin, D. Consistency of the multi-mode CMIP5/PMIP3-past1000 ensemble. Clim. Past 9, 2471-2487 (2013).

131. Landrum, L. et al. Last millennium climate and its variability in CCSM4. J. Clim. 26, 1085-1111 (2013). 


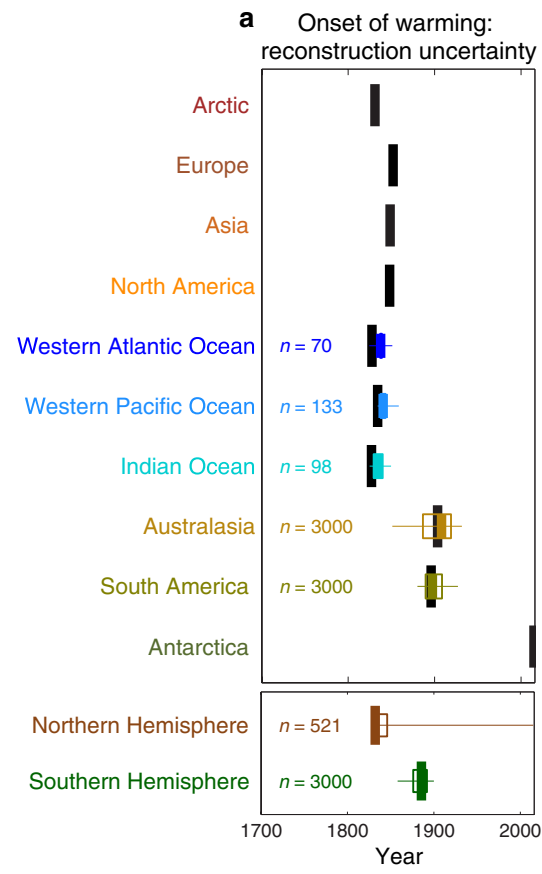

Extended Data Figure 1 | Regional distributions of onset estimates for industrial-era warming and post-AD 1800 warming trends.

a, Median (black vertical bars; as in Fig. 2a) onset of sustained, significant warming in regional reconstructions, shown with uncertainty ranges in onset estimates based on available reconstruction ensembles (colours; Methods). Distributions of onset estimates related to reconstruction uncertainty denote median (vertical bars), $25 \%-75 \%$ range (boxes) and $5 \%-95 \%$ range (horizontal lines). Distributions for the onset of warming are also calculated for Northern Hemisphere and Southern Hemisphere reconstruction ensembles ${ }^{3,5}$, with additional details in Supplementary Fig. 1. The size of reconstruction ensembles is given $(n)$. $\mathbf{b}$, As in $\mathbf{a}$, but for uncertainty ranges in onset estimates based on the SiZer changepoint detection method. Distributions (grey) denote the uncertainty in b Onset of warming: changepoint method

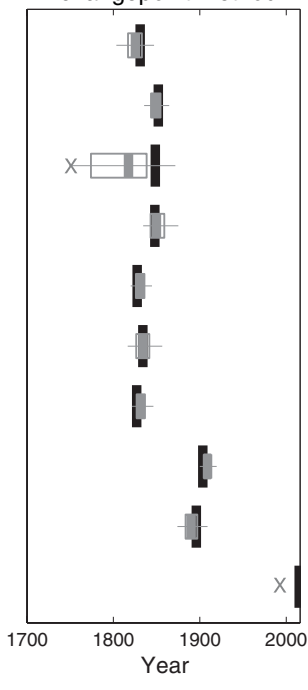

C Post-AD 1800 trend significance

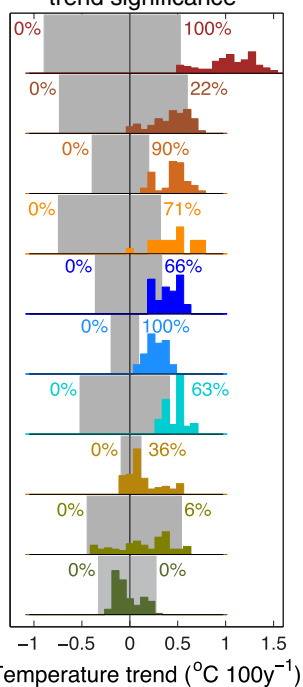

detecting a known warming onset based on synthetic tests, for which 1,000 noise series with lag- 1 autocorrelation and trend-to-variability characteristics matching the regional reconstructions are applied to an underlying trend (Methods, Extended Data Fig. 3). Crosses are used for regions for which low trend-to-variability characteristics (Antarctica) or high autocorrelation (Asia) limit the detection of a sustained, significant warming trend in the synthetic tests. c, Distribution of century-scale (100-yr) linear warming trends since AD 1800 (coloured bars), shown with reference to the $5 \%-95 \%$ range of century-scale trends beginning during the period AD 1500-1799 (grey shading). Values denote the percentage of century-scale trends since AD 1800 that lie below the 5\% level (left) or above the $95 \%$ level (right) of trends beginning during the period AD 1500-1799. 

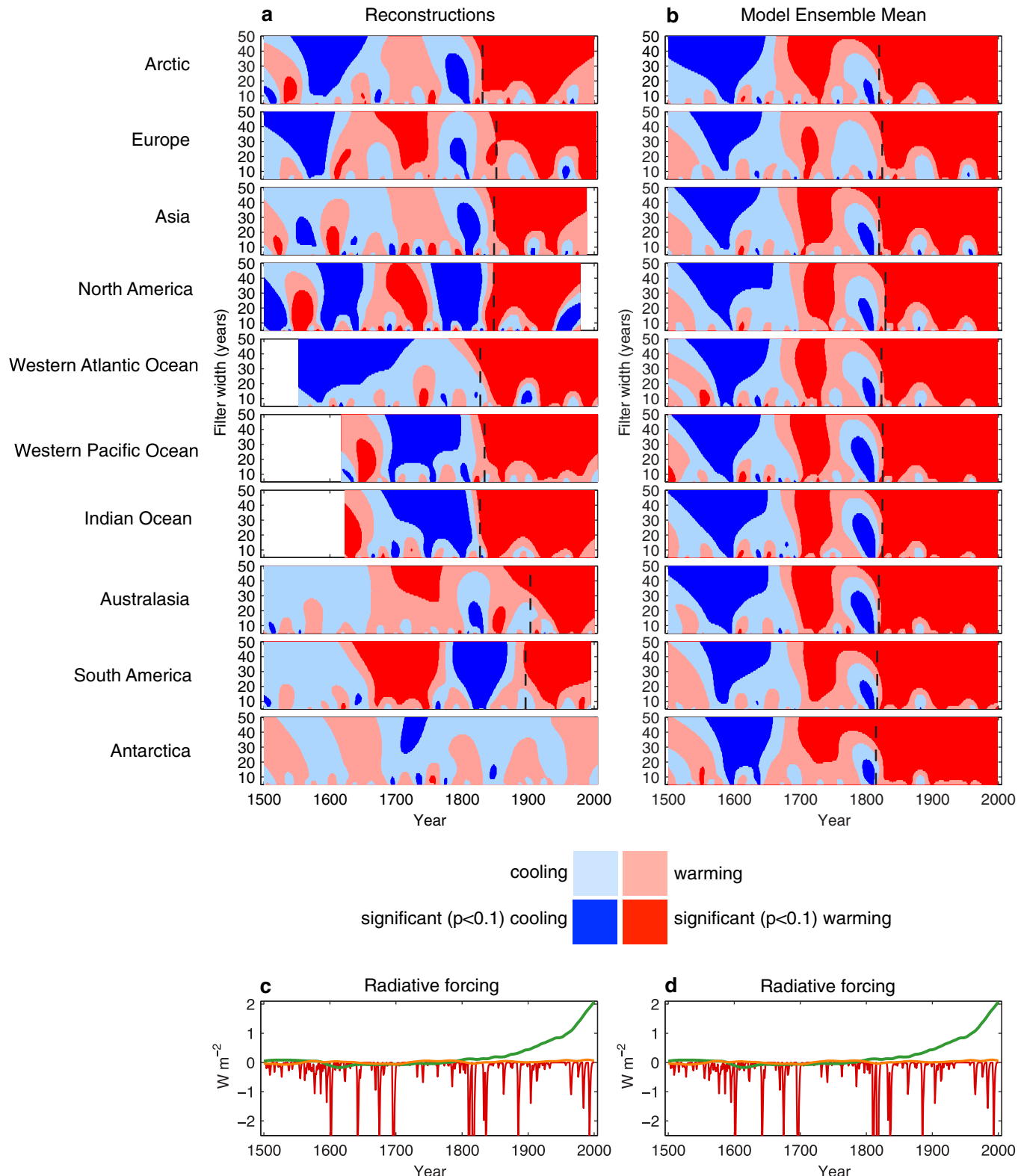

Extended Data Figure $2 \mid$ SiZer trend maps used to assess the onset of sustained, significant warming. a, SiZer trend maps ${ }^{23,24}$ for each of the regional land and ocean temperature reconstructions. The timing of warming (red) and cooling (blue) trends are calculated at different levels of smoothing. Significant $(P<0.1)$ trends are shown by dark red and dark blue shading. Vertical lines indicate the median onset time for the most recent phase of sustained, significant warming calculated across $15-50-\mathrm{yr}$ filter widths (as used in Fig. 2a; Table 1). b, As in a, but for the ensemble mean of regional surface air and surface ocean temperatures across CMIP5 last-millennium and historical model simulations. The SiZer analysis for the multi-model ensemble mean is shown for illustrative purposes only and removes the influence of unforced variability to highlight the multi-model thermodynamic response to climate forcings since AD 1500 The multi-model change-point distributions shown in Fig. 3a are based on SiZer analysis of individual experiments (Supplementary Fig. 2), not on the ensemble mean shown here. c, d, Radiative climate forcings from greenhouse (green), solar (orange) and volcanic (red) sources since $\mathrm{AD} 1500^{17,52}$. Note that the magnitude of short-term forcing from large volcanic events ${ }^{17,22}$ exceeds the lower limit of the plot axis. 
a
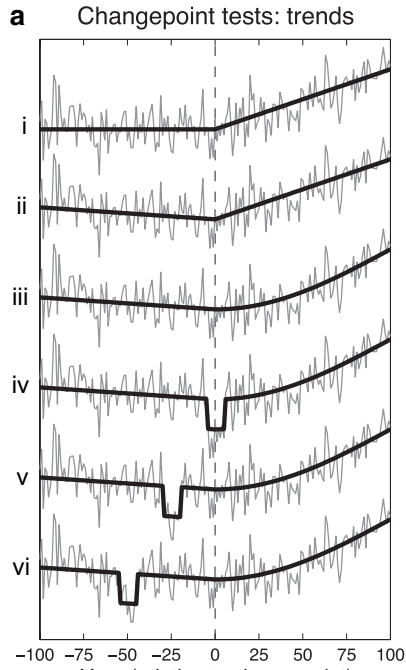

Year (relative to changepoint)

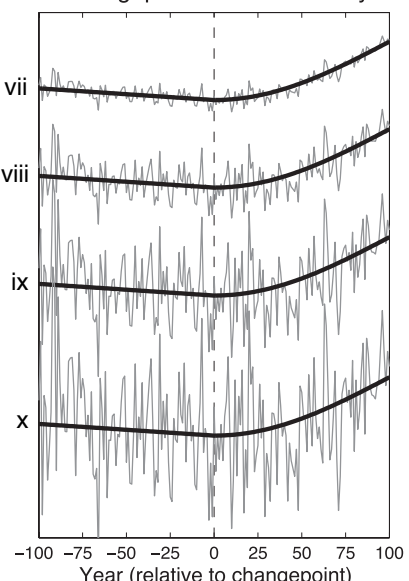

Year (relative to changepoint)

C Changepoint tests: autocorrelation

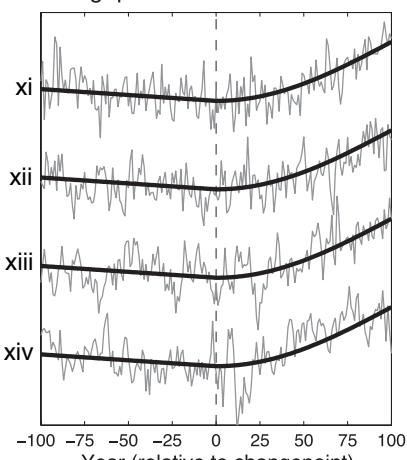

Year (relative to changepoint)
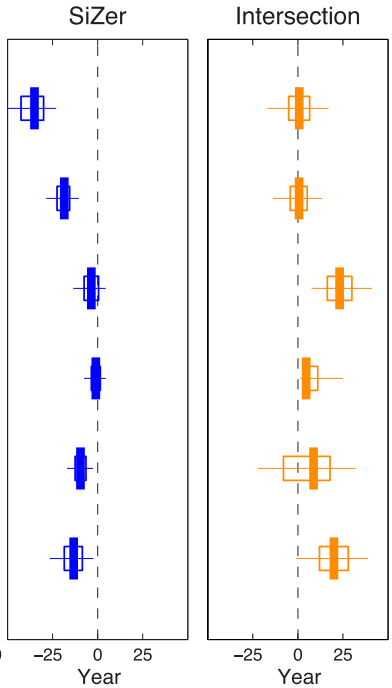

Bayesian

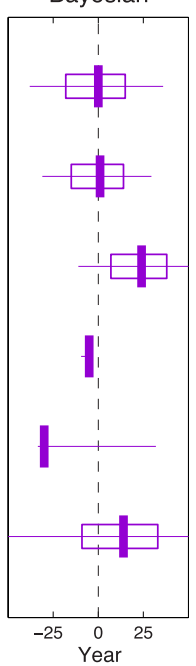

SiZer
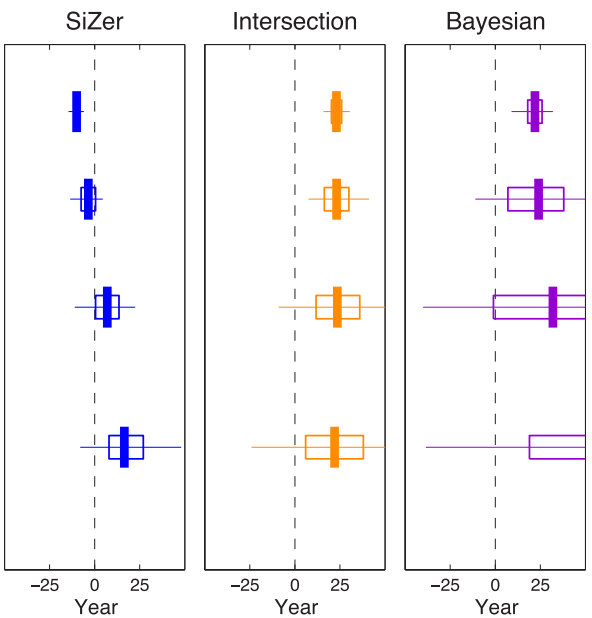

SiZer

Intersection

Bayesian
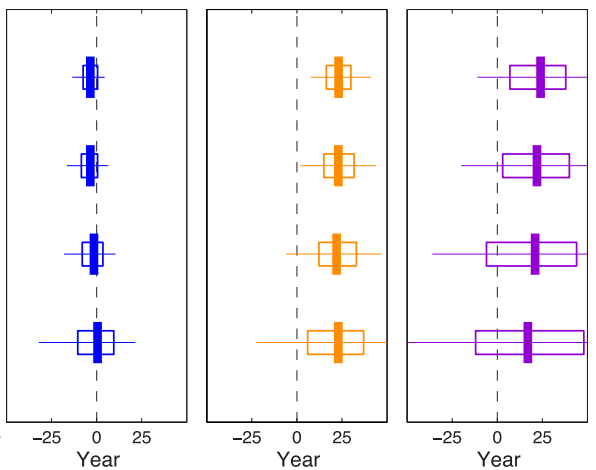

(orange) and a Bayesian linear change-point method ${ }^{54}$ (purple; screening

Extended Data Figure 3 | Assessment of change-point detection methods using synthetic time series. a, Example synthetic time series (grey), consisting of long-term trends with a change-point at year 0 (black) and $\operatorname{AR}(1)$ noise with a lag- 1 autocorrelation of 0.1 and ratio of $100-y r$ trend to $2 \sigma$ noise of 1:0.5. The synthetic trends represent: (i) no trend, then linear upward trend; (ii) small linear downward trend, then linear upward trend; (iii) small linear downward trend then accelerating upward trend (one-quarter of a period of a sine curve); (iv-vi) as in (iii), but with 10-year long downward excursions centred at 0 years (iv), -25 years (v) and -50 years (vi) relative to the onset of the accelerating upward trend. Synthetic trends are designed to capture known features of Earth's climate evolution, namely, a long-term gradual pre-industrial cooling trend followed by accelerating industrial-era warming with superimposed episodic volcanic cooling events. The distributions of change-point results using the SiZer method (blue; Methods), the best-fit intersection of two straight lines ${ }^{53}$ for one change-point and selecting the time of maximum probability) are shown for each experiment. Distributions show the median (thick vertical bars), 25\%-75\% range (boxes) and 5\%-95\% range (horizontal lines) of change-points returned across 1,000-member ensembles for each test. b, As in a, but testing the influence of different magnitudes of AR(1) noise on detecting the onset of warming in an underlying trend (using the small linear downward trend then accelerating upward trend, as in test (iii) in a). Tests use a ratio of the 100-yr trend to $2 \sigma$ noise of 1:0.2 (vii), 1:0.5 (viii), 1:1 (ix) and 1:1.5 (x). c, As in $\mathbf{b}$, but testing the influence of different AR(1) autocorrelation on detecting the onset of warming in an underlying trend. Tests use lag-1 autocorrelations of 0.1 (xi), 0.3 (xii), 0.5 (xiii) and 0.7 (xiv). See Methods for a detailed discussion of these change-point method tests and Extended Data Fig. 1b for application of the SiZer method tests using signal-to-noise parameters applicable to the regional reconstructions. 


\section{RESEARCH ARTICLE}

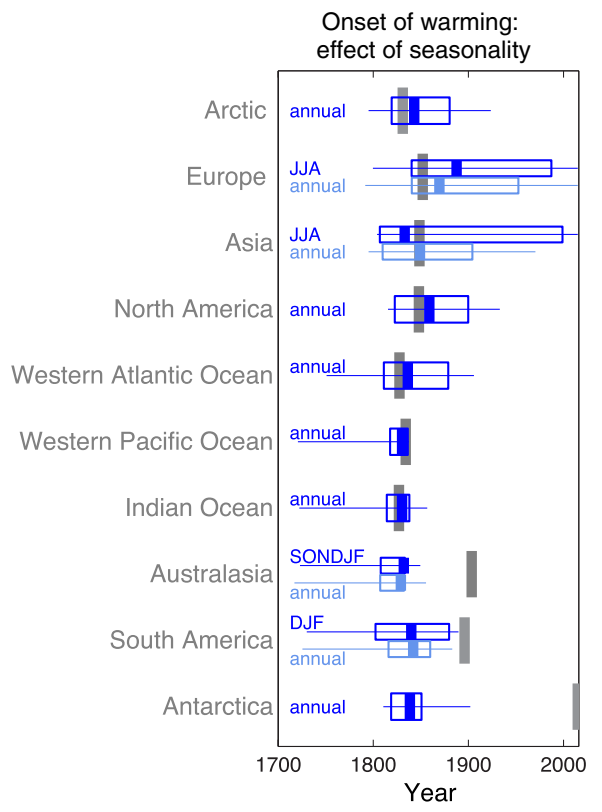

Extended Data Figure 4 | Sensitivity of the onset of sustained, significant warming to seasonality. Median onset of sustained,

significant warming in regional reconstructions (grey vertical bars; as in Fig. 2a), shown against the median (blue vertical bars), 25\%-75\% range (boxes) and 5\%-95\% range (horizontal lines) of corresponding regional median warming onsets across ten multi-model last-millennium climate simulations with full radiative forcings. Dark blue distribution plots (as in Fig. 3a) show the onset of warming for regions for which regional temperature information from the models has been extracted for annual or season-specific intervals that match the climate representation of the regional reconstructions (as defined in refs 4,14 ). For comparison, light blue distributions show the model results for the median onset of sustained, significant warming using annual average data for the reconstruction regions with a seasonal preference (Europe, Asia, Australasia and South America). The similarity between change-point results based on annual average and season-specific model data suggests that it is unlikely that seasonality plays a role in the regional characteristics of the onset of sustained, significant warming described here. JJA,

June-August; SONDJF; September-February; DJF, December-February. 




- 15y filter $30 y$ filter

- 20y filter 40y filter

- 25y filter $50 y$ filter

Extended Data Figure $5 \mid$ Sensitivity of the onset of sustained,

significant warming to filter width. Distributions across $15-50$-yr filter widths for the regional onset of sustained, significant warming (Extended Data Fig. 2a) showing the median (grey vertical bars), 25\%-75\% range (grey boxes) and 5\%-95\% range (grey horizontal lines). Coloured circles demonstrate the change-points determined at specific filter widths, with markers at $\mathrm{AD} 2015$ indicating that a sustained recent warming is not detected. With the exception of Antarctica, for which significant warming is not observed at any filter width, the change-point analysis shows that shorter filter widths (less smoothing) yield more recent onset dates for sustained warming. This is because decadal-scale variability resets the time over which significant warming is determined to have been sustained in records with less smoothing. This effect accounts for the wide rightside tails produced in warming onset distributions for the Northern Hemisphere reconstruction regions for which decadal-scale variability is particularly strong (Fig. 2). 

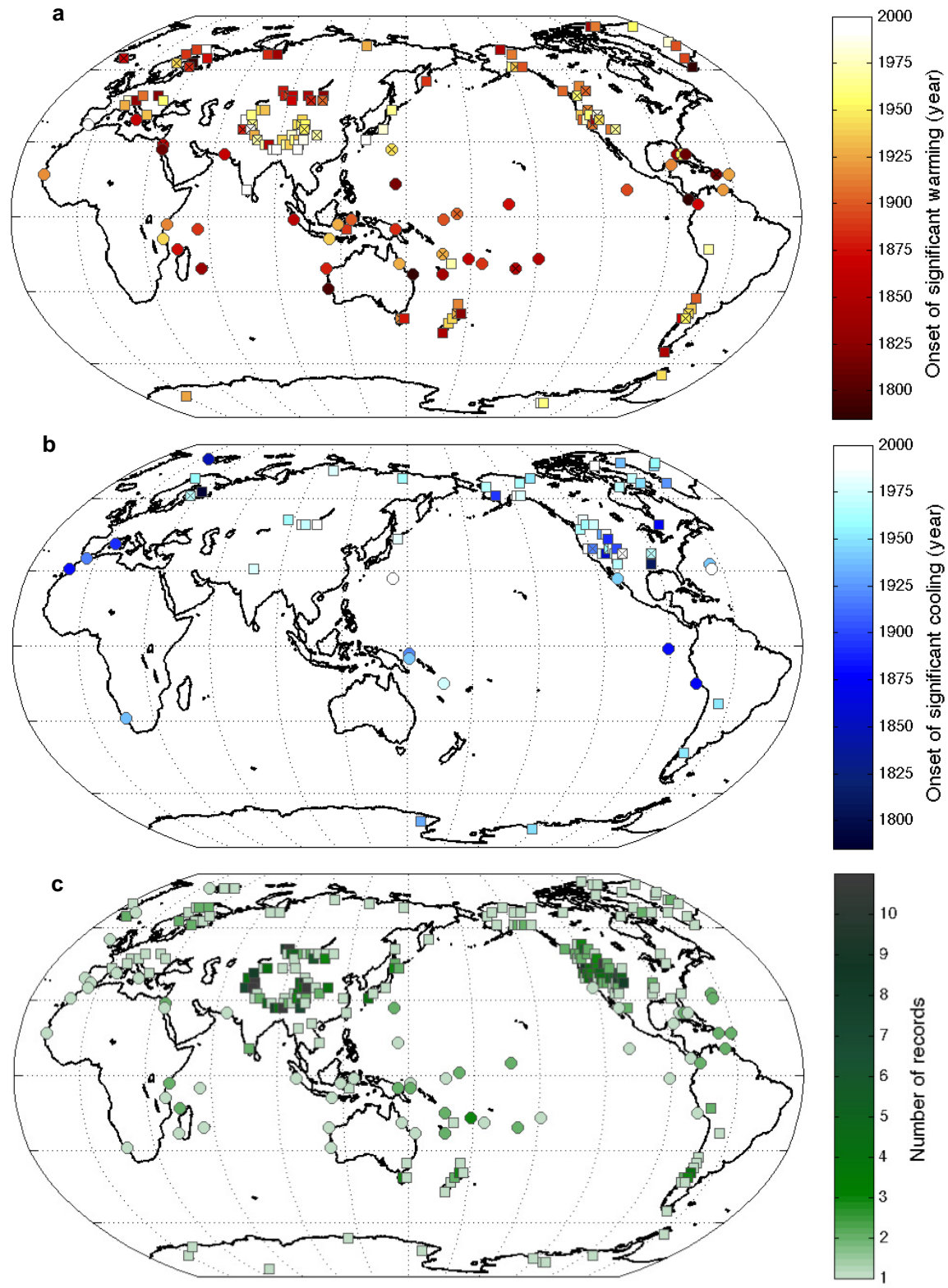

Extended Data Figure 6 | Site-level onset of sustained, significant trends. a, b, The same SiZer-based trend analysis performed on the regional reconstructions (Methods, Fig. 2a) was applied to individual temperature-sensitive marine and terrestrial records ${ }^{4,14-16}$ to determine the median time of onset of sustained, significant industrial-era warming (a) or cooling (b) trends. c, Number of records available in a $2^{\circ} \times 2^{\circ}$ grid region (maximum $n=28$ ). Where multiple site-level records are available in a $2^{\circ} \times 2^{\circ}$ grid, the median-of-medians change-point is shown in $\mathbf{a}$ or $\mathbf{b}$ Symbols are crossed in $\mathbf{a}$ and $\mathbf{b}$ if the interquartile range (25-75 percentile range) of change-points within a grid box exceeds 80 years. In all plots, terrestrial data are shown as squares and marine data are shown as circles. The onset of site-level warming and cooling trends is compiled by latitudinal band in Fig. 4. 


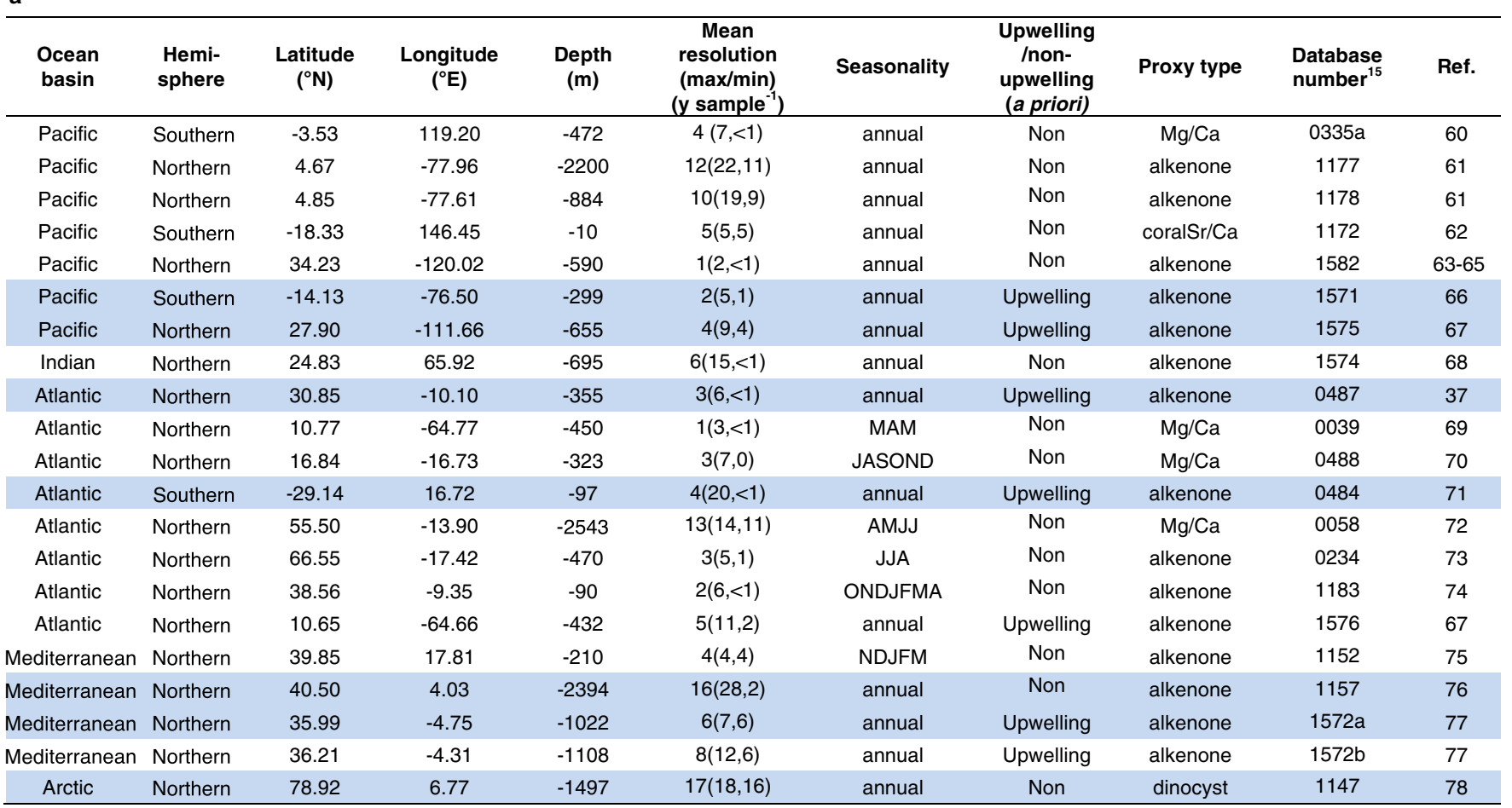
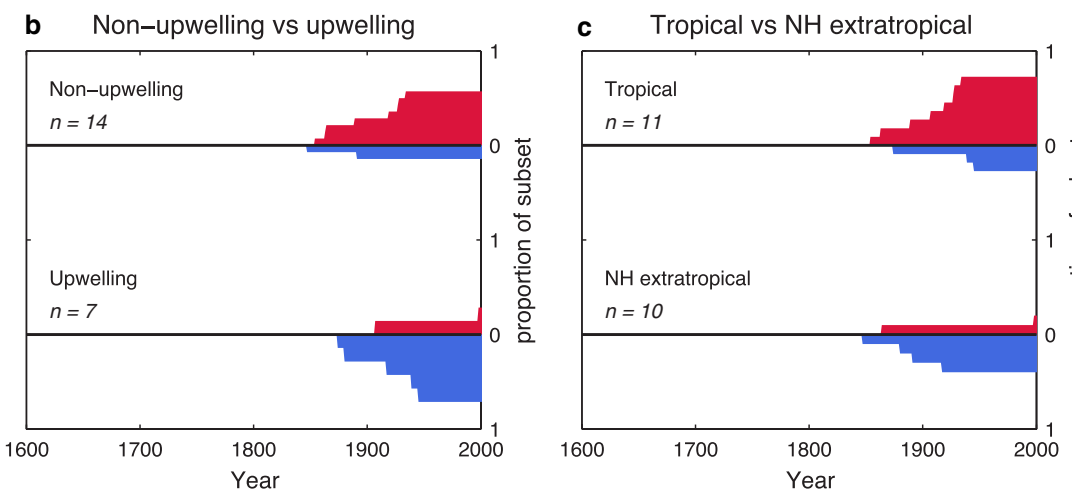

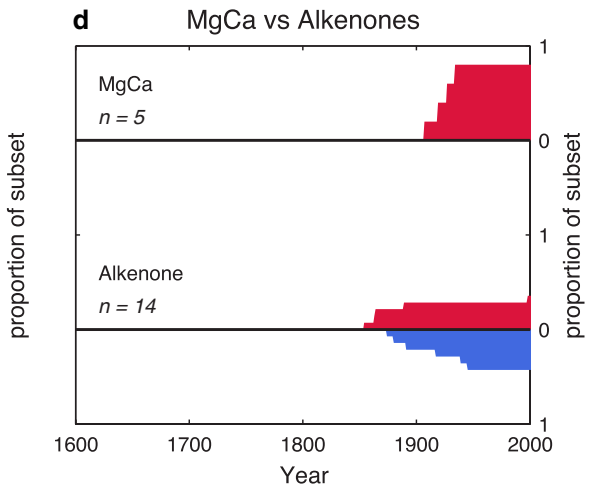

in a denotes records for which SiZer analysis detects recent significant cooling trends. The subsets of moderately resolved marine records produce the best differentiation between recent warming and cooling trends when the site-level change-point results are grouped according to non-upwelling (warming) and upwelling (cooling) sites. This suggests that enhanced ocean upwelling during the industrial era may provide a more robust mechanism to account for recent cooling trends in some localized parts of the world oceans, rather than differentiation based on latitude or geochemical analysis type. $\mathrm{NH}$, Northern Hemisphere. 
a
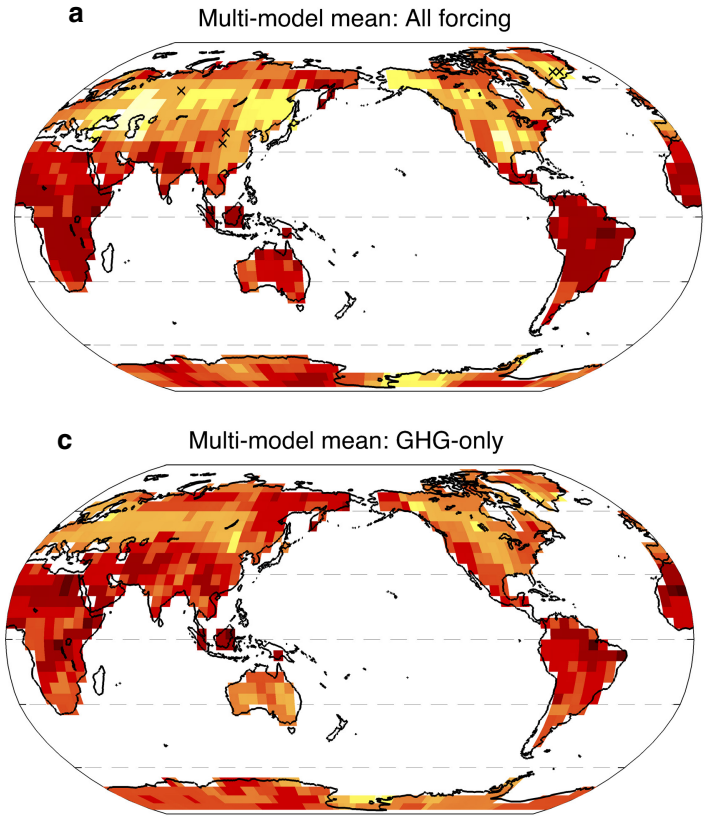

b Multi-model mean: All forcing

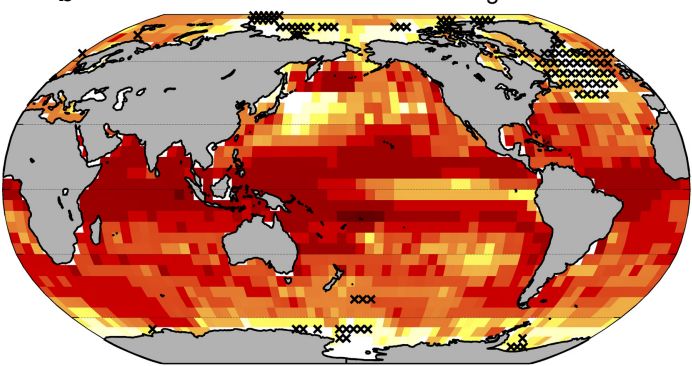

d Multi-model mean: GHG-only

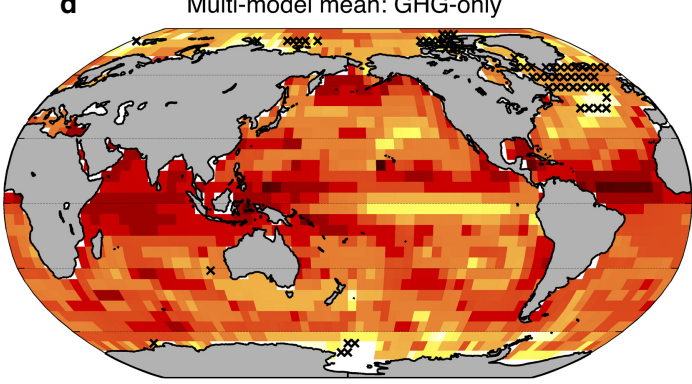



Extended Data Figure $8 \mid$ Onset of sustained, significant warming trends in climate simulations. The same SiZer-based change-point analysis performed on the regional reconstructions (Methods) was applied to climate simulations compiled at $5^{\circ} \times 5^{\circ}$ grid resolution to determine the spatial fingerprint for the onset of industrial-era trends. a, b, The multimodel mean for the onset of sustained, significant warming in surface air temperature (a) and sea surface temperature (b) calculated for the first ensemble member of LOVECLIM, CSIRO Mk3L, CCSM4 and HadCM3 last-millennium experiments with full transient radiative forcings ('All forcing'). c, d, As in $\mathbf{a}$ and $\mathbf{b}$, but for the first ensemble member of greenhouse-only ('GHG-only') forced experiments of the same models. Crosses indicate grid boxes in which one or more models produce recent significant cooling rather than warming trends. See Supplementary Fig. 3 for results from individual models. In the subset of models examined here, the fingerprint of warming onset across the oceans is characterized by early warming of most tropical ocean regions except the equatorial eastern Pacific. Delayed warming-or cooling-occurs in the North Atlantic, Arctic and Southern Oceans. The onset of sustained warming is delayed at the grid level in many terrestrial parts of the Northern Hemisphere midto high latitudes, owing to large decadal-scale model variability over these regions, a feature that is reduced (but still evident; Extended Data Fig. 5) in regionally averaged climate data. The delayed onset of Antarctic warming is not evident in this grid-level assessment, consistent with Southern Hemisphere data-model disagreement observed in regionally averaged data. 
Extended Data Table 1 | High-resolution, SST-sensitive coral data compiled by the Ocean2k project

\begin{tabular}{|c|c|c|c|c|c|c|c|}
\hline $\begin{array}{l}\text { Reconstruction } \\
\text { region }\end{array}$ & $\begin{array}{c}\text { Latitude } \\
\left({ }^{\circ} \mathrm{N}\right)\end{array}$ & $\begin{array}{c}\text { Longitude } \\
\left({ }^{\circ} \mathrm{E}\right)\end{array}$ & Site name & Coral genus & Sampling resolution & Proxy type & References \\
\hline western Pacific & 27.10 & 142.20 & Chichijima & Porites & seasonal & $\mathrm{Sr} / \mathrm{Ca}$ & 79 \\
\hline western Pacific & 27.10 & 142.20 & Chichijima & Porites & seasonal & $\delta^{18} \mathrm{O}$ & 79 \\
\hline western Pacific & 13.60 & 144.83 & Double Reef & Porites & monthly & $\delta^{18} \mathrm{O}$ & 80 \\
\hline western Pacific & -8.26 & 115.57 & Bali & Porites & monthly & $\delta^{18} \mathrm{O}$ & 81 \\
\hline western Pacific & -1.50 & 124.83 & Bunaken & Porites & monthly & $\delta^{18} \mathrm{O}$ & 81 \\
\hline western Pacific & -17.50 & -149.83 & Moorea & Porites & annual & $\delta^{18} \mathrm{O}$ & 82,83 \\
\hline western Pacific & -5.22 & 145.82 & Madang & Porites & seasonal & $\delta^{18} \mathrm{O}$ & 84 \\
\hline western Pacific & -4.15 & 144.88 & Liang & Porites & seasonal & $\delta^{18} \mathrm{O}$ & 84 \\
\hline western Pacific & -2.50 & 150.5 & Kavieng & Porites & monthly & $\mathrm{Sr} / \mathrm{Ca}$ & 85 \\
\hline western Pacific & -4.18 & 151.98 & Rabul & Porites & monthly & $\delta^{18} \mathrm{O}$ & 86 \\
\hline western Pacific & -4.18 & 151.98 & Rabul & Porites & monthly & $\mathrm{Sr} / \mathrm{Ca}$ & 86 \\
\hline western Pacific & -21.24 & -159.83 & Raratonga* & Porites & seasonal & $\delta^{18} \mathrm{O}$ & 87 \\
\hline western Pacific & -21.24 & -159.83 & Raratonga* & Porites & seasonal & $\mathrm{Sr} / \mathrm{Ca}$ & 87 \\
\hline western Pacific & -15.00 & 166.99 & Espiritu Santo & Porites & annual & $\delta^{18} \mathrm{O}$ & 88 \\
\hline western Pacific & -15.94 & 166.04 & Sabine Bank* & Porites & monthly & $\delta^{18} \mathrm{O}$ & 89 \\
\hline western Pacific & -22.29 & 166.27 & Amedee Island* & Porites & monthly & $\mathrm{Sr} / \mathrm{Ca}$ & 90,91 \\
\hline western Pacific & -22.48 & 166.47 & Amadee Island & Porites & seasonal & $\delta^{18} \mathrm{O}$ & 92 \\
\hline western Pacific & -16.82 & 179.23 & Suvasuva Bay & Diploastrea & annual & $\delta^{18} \mathrm{O}$ & 93 \\
\hline western Pacific & -16.82 & 179.23 & Suvasuva Bay* & Porites & annual & $\delta^{18} \mathrm{O}$ & 87 \\
\hline western Pacific & -16.82 & 179.23 & Suvasuva Bay & Porites & annual & $\mathrm{Sr} / \mathrm{Ca}$ & 87 \\
\hline western Pacific & -21.91 & 113.97 & Ningaloo Reef & Porites & seasonal & $\delta^{18} \mathrm{O}$ & 94 \\
\hline western Pacific & -22.10 & 153.00 & Abraham Reef & Porites & annual & $\delta^{18} \mathrm{O}$ & 95 \\
\hline western Pacific & -19.90 & -174.70 & Tonga & Porites & annual & $\mathrm{Sr} / \mathrm{Ca}$ & 96 \\
\hline eastern Pacific & 10.28 & -109.21 & Clipperton Atoll ${ }^{*}$ & Porites & seasonal & $\delta^{18} \mathrm{O}$ & 97 \\
\hline eastern Pacific & -0.40 & -91.23 & Urvina Bay* & Porites & annual & $\delta^{18} \mathrm{O}$ & 98 \\
\hline eastern Pacific & 1.00 & 173.00 & Maiana Atoll & Porites & seasonal & $\delta^{18} \mathrm{O}$ & 99 \\
\hline eastern Pacific & 1.00 & 172.00 & Tarawa Atoll & Porites & monthly & $\delta^{18} \mathrm{O}$ & 100,101 \\
\hline eastern Pacific & -0.53 & 166.93 & Nauru* & Porites & seasonal & $\delta^{18} \mathrm{O}$ & 102 \\
\hline eastern Pacific & 7.95 & -82.00 & Secas Island & Porites & seasonal & $\delta^{18} \mathrm{O}$ & 103 \\
\hline eastern Pacific & 5.87 & -162.13 & Palmyra Atoll ${ }^{\star}$ & Porites & monthly & $\delta^{18} \mathrm{O}$ & 104 \\
\hline eastern Pacific & 5.87 & -162.13 & Palmyra Atoll & Porites & monthly & $\mathrm{Sr} / \mathrm{Ca}$ & 105,106 \\
\hline Indian & -3.00 & 40.00 & Malindi & Porites & annual & $\delta^{18} \mathrm{O}$ & 107 \\
\hline Indian & -12.65 & 45.10 & Mayotte & Porites & seasonal & $\delta^{18} \mathrm{O}$ & 108,109 \\
\hline Indian & -12.65 & 45.10 & Mayotte & Porites & seasonal & $\mathrm{Sr} / \mathrm{Ca}$ & 108,109 \\
\hline Indian & -23.15 & 43.58 & Ifaty Reef & Porites & seasonal & $\delta^{18} \mathrm{O}$ & 110 \\
\hline Indian & -28.46 & 113.77 & Houtman Abrolhos & Porites & seasonal & $\delta^{18} \mathrm{O}$ & 111 \\
\hline Indian & -8.02 & 39.50 & Mafia Island & Diploastrea & seasonal & $\delta^{18} \mathrm{O}$ & 112 \\
\hline Indian & -0.13 & 98.52 & Mentawai* & Porites & monthly & $\delta^{18} \mathrm{O}$ & 113 \\
\hline Indian & -4.62 & 55.00 & Mahe, Seychelles & Porites & monthly & $\delta^{18} \mathrm{O}$ & 114 \\
\hline Indian & -3.20 & 40.10 & Malindi & Porites & monthly & $\delta^{18} \mathrm{O}$ & 115 \\
\hline Indian & -21.00 & 55.00 & La Reunion & Porites & seasonal & $\delta^{18} \mathrm{O}$ & 116 \\
\hline Indian & 29.43 & 34.97 & Aquaba* & Porites & annual & $\delta^{18} \mathrm{O}$ & 117 \\
\hline Indian & 27.85 & 34.31 & Ras Um Sidd* & Porites & seasonal & $\delta^{18} \mathrm{O}$ & 118 \\
\hline Indian & 27.85 & 34.32 & Ras Um Sidd & Porites & seasonal & $\delta^{18} \mathrm{O}$ & 119 \\
\hline western Atlantic & 30.65 & -64.99 & Bermuda & Diploria & annual & $\delta^{18} \mathrm{O}$ & 120 \\
\hline western Atlantic & 30.65 & -64.99 & Bermuda & Diploria & annual & $\mathrm{Sr} / \mathrm{Ca}$ & 120 \\
\hline western Atlantic & 16.20 & -61.49 & Guadeloupe & Diploria & monthly & $\delta^{18} \mathrm{O}$ & 121 \\
\hline western Atlantic & 16.20 & -61.49 & Guadeloupe & Diploria & monthly & $\mathrm{Sr} / \mathrm{Ca}$ & 121 \\
\hline western Atlantic & 17.93 & -67.00 & Puerto Rico & Montastrea & annual & $\delta^{18} \mathrm{O}$ & 122 \\
\hline western Atlantic & 17.93 & -67.00 & Puerto Rico & Montastrea & annual & $\mathrm{Sr} / \mathrm{Ca}$ & 122 \\
\hline western Atlantic & 32.47 & -64.70 & Bermuda & Diploria & monthly & $\delta^{18} O$ & 123 \\
\hline western Atlantic & 32.47 & -64.70 & Bermuda & Diploria & monthly & $\mathrm{Sr} / \mathrm{Ca}$ & 123 \\
\hline western Atlantic & 24.93 & -80.75 & Florida Bay & Solenastrea & annual & $\delta^{18} \mathrm{O}$ & 124 \\
\hline western Atlantic & 25.38 & -80.17 & Biscayne, Florida & Montastrea & annual & $\delta^{18} \mathrm{O}$ & 125 \\
\hline western Atlantic & 25.84 & -78.62 & Bahamas & Siderastrea & annual & growth rate & 126 \\
\hline western Atlantic & 20.83 & -86.74 & Yucatan* & Siderastrea & annual & growth rate & 127 \\
\hline western Atlantic & 24.66 & -82.83 & Dry Tortugas* & Siderastrea & monthly & $\mathrm{Sr} / \mathrm{Ca}$ & 128 \\
\hline
\end{tabular}

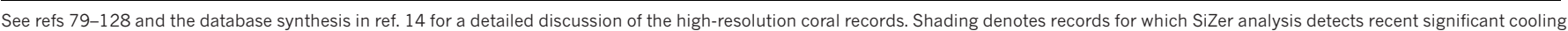

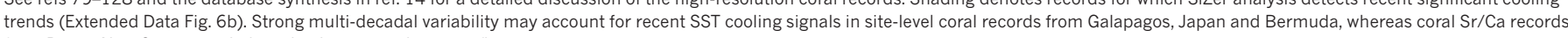
from Papua New Guinea are believed to have non-climatic influences.

*Composite of multiple coral records. 
RESEARCH ARTICLE

Extended Data Table 2 | Details of the last-millennium and historical climate simulations

\begin{tabular}{|c|c|c|c|c|c|}
\hline \multirow{2}{*}{ Model } & \multicolumn{2}{|c|}{ Sea surface temperature (tos files) } & \multicolumn{2}{|c|}{ Surface air temperature (tas files) } & \multirow{2}{*}{ References } \\
\hline & Last Millennium & Historical & Last Millennium & Historical & \\
\hline BCC-CSM1.1 & past1000_r1i1p1 & past1000_r1i1p1 & past1000_r1i1p1 & past1000_r1i1p1 & $\begin{array}{c}\text { http://forecast.bcccsm.ncc } \\
\text {-cma.net /web/channel- } \\
\text { 43.htm }\end{array}$ \\
\hline MIROC-ESM & past1000_r1i1p1 & historical_r1i1p1 & past1000_r1i1p1 & historical_r1i1p1 & 129 \\
\hline IPSL CM5A-LR & not available & not available & past1000_r1i1p1 & historical_r1i1p1 & $\begin{array}{l}\text { http://icmc.ipsl.fr/index.ph } \\
\text { p/cmip5 }\end{array}$ \\
\hline MPI-ESM-P & past1000_r1i1p1 & historical_r1i1p1 & past1000_r1i1p1 & thistorical_r1i1p1 & $\begin{array}{l}130 \\
\text { http://www.mpimet.mpg.d } \\
\text { e/en/science/models/mpi- } \\
\text { esm.html }\end{array}$ \\
\hline NCAR CCSM4 & past1000_r1i1p1 & historical_r1i1p1 & past1000_r1i1p1 & historical_r1i1p1 & $\begin{array}{c}131 \\
\text { http://www.cesm.ucar.edu } \\
\text { /experiments/ }\end{array}$ \\
\hline HadCM3 & past1000_r1i1p1 & pers. comm & past1000_r1i1p1 & pers. comm & 20 \\
\hline GISS-E2-R* & past1000_r1i1p124 & historical_r1i1p124 & past1000_r1i1p124 & historical_r1i1p124 & $\begin{array}{l}\text { http://data.giss.nasa.gov/ } \\
\text { modelE/ar5/ }\end{array}$ \\
\hline FGOALS-s2 & past1000_r1i1p1 & pers. comm & not available & not available & \\
\hline LOVECLIM† & \multicolumn{2}{|c|}{ Full forcing (10 member ensemble; e1-e10) } & \multicolumn{2}{|c|}{ Full forcing (10 member ensemble; e1-e10) } & 18 \\
\hline LOVECLIM & \multicolumn{2}{|c|}{ Greenhouse only ( 3 member ensemble) } & \multicolumn{2}{|c|}{ Greenhouse only (3 member ensemble) } & 18 \\
\hline LOVECLIM & \multicolumn{2}{|c|}{ Solar only (3 member ensemble) } & \multicolumn{2}{|c|}{ Solar only (3 member ensemble) } & 18 \\
\hline LOVECLIM & \multicolumn{2}{|c|}{ Volcanic only (3 member ensemble) } & \multicolumn{2}{|c|}{ Volcanic only ( 3 member ensemble) } & 18 \\
\hline CSIRO-Mk3L v1.2 & \multicolumn{2}{|c|}{ Orbital + Greenhouse (3 member ensemble) } & \multicolumn{2}{|c|}{ Orbital + Greenhouse (3 member ensemble) } & 21 \\
\hline CSIRO-Mk3L v1.2 & \multicolumn{2}{|c|}{$\begin{array}{c}\text { Orbital + Greenhouse + Solar } \\
\text { (3 member ensemble })\end{array}$} & \multicolumn{2}{|c|}{ Orbital + Greenhouse + Solar } & 21 \\
\hline CSIRO-Mk3L v1.2† & \multicolumn{2}{|c|}{$\begin{array}{c}\text { Orbital }+ \text { Greenhouse }+ \text { Solar }+ \text { Volcanic } \\
(3 \text { member ensemble })\end{array}$} & \multicolumn{2}{|c|}{ Orbital + Greenhouse + Solar + Volcanic } & 21 \\
\hline HadCM3 & Greenhouse onl & mber ensemble) & Greenhouse only & mber ensemble) & 20 \\
\hline NCAR CESM1 & Greenhouse onl & mber ensemble) & Greenhouse only & ember ensemble) & 19 \\
\hline
\end{tabular}

This table includes CMIP5 experiment and ensemble member identification and details of additional idealized forcing experiments ${ }^{18-21,129-131}$ (see also http://forecast.bcccsm.ncc-cma.net/web/

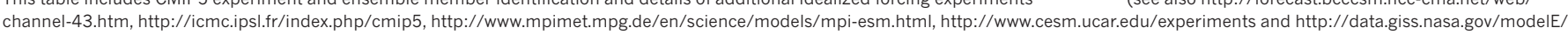

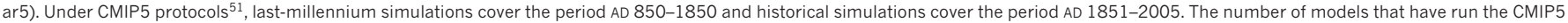
transient last-millennium experiment is smaller than the full set of CMIP5 climate models.

*Experiment 24 of GISS-E2-R last-millennium ensemble is used for the multi-model assessment (Fig. 3a). The GISS-E2-R ensembles use different combinations of datasets for solar forcing, volcanic forcing and land-use change, but do not include specialized single or cumulative forcing experiments such as those analysed in Fig. 3b-d.

†The first ensemble members of these experiments contribute to the multi-model assessment (Fig. 3a). 